\title{
The Expansion of tree-based boom crops in Mainland Southeast Asia: 2001 to 2014
}

Kaspar Hurni ${ }^{1, *}$ and Jefferson Fox ${ }^{2}$

${ }^{1}$ East-West Center, 1601 East-West Road, Honolulu, HI 96848, USA; and University of Bern, Centre for Development and Environment (CDE), Hallerstr. 10, CH-3012 Bern, Switzerland; $e$ mail: kaspar.hurni@cde.unibe.ch; Tel: +41 3163188 22; ORCID: 0000-0001-7660-3404

${ }^{2}$ East-West Center, 1601 East-West Road, Honolulu, HI 96848, USA; e-mail:

FoxJ@EastWestCenter.org; Tel: +1 (808) 9447111

* correspondence: kaspar.hurni@ cde.unibe.ch; Tel: +41316318822

Word count: 10,011

Geolocation: Mainland Southeast Asia (Cambodia, Laos, Myanmar, Thailand, and Vietnam);

Centerpoint: $103^{\circ} 27^{\prime} 37.596 " \mathrm{E} / 17^{\circ} 35^{\prime} 15.868^{\prime \prime} \mathrm{N}$

Supplemental material: Classification samples (point Shapefile) and classification results (GeoTIFF) can be downloaded at: https://scholarspace.manoa.hawaii.edu/handle/10125/54254

Acknowledgments: This study was supported by the National Aeronautics and Space Administration's (NASA) Land-Cover and Land-Use Change Program (LCLUC) Grant No. NNX14AD87G. We thank NASA's LCLUC Program for its support. We would also like to thank Annemarie Schneider and Andreas Heinimann for their inputs and backstopping.

Author Contributions: Kaspar Hurni and Jefferson Fox conceived and designed the study; Kaspar Hurni performed the image classification; Jefferson Fox and Kaspar Hurni analyzed and interpreted the data and results; Jefferson Fox and Kaspar Hurni wrote the paper.

Conflicts of Interest: The authors declare no conflict of interest. 


\begin{abstract}
Over the past half century, countries of Mainland Southeast Asia (MSEA) Cambodia, Laos, Myanmar, Thailand, and Vietnam - have witnessed increases in commercialized agriculture with rapid expansions of boom-crop plantations. We used MODIS EVI and SWIR time-series from 2001-2014 to classify tree-cover changes across MSEA and performed a supervised change detection using an upscaling approach by deriving samples from existing Landsat classifications. We used the random forest classifier and distinguished 24 classes (16 representing boom-crops) with an accuracy of $82.2 \%$. Boom-crops occupy about $18 \%$ of the landscape (8\% of which is rubber). Since $200374,960 \mathrm{~km}^{2}$ of rubber have been planted; 70\% of rubber is planted on former forest land, and 30\% on low vegetation area (mainly former croplands). Timing, patterns of change, and deforestation rates, however, differ among the MSEA countries and the high spatial and temporal detail of our classification allowed us to quantify dynamics and discuss political and socio-economic drivers of change.
\end{abstract}

Keywords: MODIS, random forest classifier, Mainland Southeast Asia, land-cover change, boom-crops, remote sensing 


\section{Introduction}

Since the early 1980s the five countries of Mainland Southeast Asia (MSEA), Cambodia, Laos, Myanmar, Thailand, and Vietnam, have experienced dramatic changes in rural land-use and social relations (Baird, 2011; Hall, Hirsch, \& Li, 2011; Lestrelin, Castella, \& Fox, 2013). Some of the main processes behind these changes (economic growth, industrialization, and urbanization) have driven the conversion of a great deal of agricultural land to commercial, industrial, residential, tourist and infrastructural uses. Processes working against agriculture, however, coexist with forces that speak to the continuing importance of farming. National policies have led to agricultural intensification and the linking of smallholder production systems to land, labor and commodities markets. In a recent survey of agrarian change in Southeast Asia, Hall et al. (2011) identified major land-cover transitions associated with ongoing socio-economic and political changes. These included loss and gain of forests, agricultural intensification and extensification including boom crops, and urbanization.

Between 1990 and 2010 forest cover in MSEA fell from 50.7 to 45.7\%, particularly as a result of losses in Cambodia, Laos and Myanmar, although certain tree crop types (e.g. rubber, coconut, oil-palms) may be included in the forest definition (FAO, 2011). In Thailand, some forests are beginning to regrow on former cropland (Leblond, 2008). In Vietnam, large governmentsupported afforestation and reforestation programs are resulting in forest expansion, although, as in almost all countries in the region, primary forests are still being lost at high rates (Meyfroidt \& Lambin, 2009). Boom crops are crops that witness rapid and extensive expansion usually triggered by increased market incentives and favorable policies, e.g., promoting agricultural transformation in the form of smallholder market integration and large scale plantations (Hall et al., 2011). Among the many types of commercial boom crops promoted in MSEA are numerous 
tree-based products such as rubber, coffee, tree species for pulp and paper (particularly eucalyptus and acacia), cashews, and fruits (e.g. oranges, lychees, and longans), but also nontree-based boom crops, such as sugarcane.

The investment of political and financial capital these developments represent, and the concomitant shifts in livelihood strategies and land-use patterns that accompany them have important social and ecological implications. Boom crops are marked by both agricultural intensification (i.e. subsistence agriculture or agro-forests are converted to new boom crops (rubber, cashews, coffee)) as well as agricultural expansion (i.e. forested lands are converted to new tree crops). We began this study with the hypothesis that most (but not all) tree-based boom crops in MSEA were marked by intensification of previously used agricultural land that was not necessarily accompanied by deforestation, but the intensification may push subsistence land-uses elsewhere.

Monitoring change in tree-dominated landscapes in MSEA is challenging because the processes of change affect the diversity of replacement crops. For example, the secondary forests associated with shifting cultivation can either be deforested or afforested depending on whether they are replaced by a variety of tree crops (rubber, oil palm, coffee) or the expansions of permanent agriculture (sugar cane, cassava) (Suepa, Qi, Lawawirojwong, \& Messina, 2016; Tottrup, Rasmussen, Eklundh, \& Jönsson, 2007). This study sought to document changes in tree cover at the regional scale and we used time-series of MODIS 16-day image composites to map changes in forests and tree-boom crops from 2001-2014 in parts of four MSEA countries: Thailand, Laos, Cambodia, and Vietnam, as well as in Shan State Myanmar, and Xishuangbanna Prefecture in southern Yunnan, China (Z. Li \& Fox, 2011). The MODIS classification builds on our previous work at the local scale using Landsat imagery to map land-cover dynamics from 
2000-2014 for selected Landsat footprints in Laos, Cambodia, Thailand, and Myanmar (cf Hurni, Schneider, Heinimann, Nong, \& Fox, 2017).

This paper seeks to report the extent of tree-based boom crops in the study region in 2014; and the expansion of rubber between 2003 and 2014. We produced an up-to-date map that depicts the precise from-to (i.e., from evergreen forests, deciduous forests, or permanent agriculture to tree crop) trajectory, location, extent (useful for separating smallholders from large-scale concessions), and timing of recent changes. The paper does not present an extensive discussion of the political and economic conditions under which crop booms occur (see for instance De Koninck, 2006; De Koninck, Bernard, \& Bissonnette, 2011; Gérard \& Ruf, 2001; Hall, 2003; Hall et al., 2011; Ziegler, Fox, \& Xu, 2009). This paper builds on previous work done by Hurni et al. (2017) on selected Landsat footprints and expands the classification to the MSEA region using MODIS time-series data to provide insights into the political and economic conditions under which these changes occurred.

\section{Background}

Hall et al. (2011) argue that the Southeast Asian literature permits a broad distinction between booms that have taken place under 'secure' conditions and those that have not. 'Insecure' booms take place in areas that are often conceptualized as 'frontiers', areas imagined by national leaders and others to be 'resource frontiers', with low population densities, available land, and underutilized resources (see Barney, 2008). In reality, these places are almost always occupied by small-scale farmers, especially upland minorities who have often lived there for generations (Baird, 2010, 2011), and practiced subsistence agriculture (Fox \& Vogler, 2005; Schmidt-Vogt et al., 2009). In 'secure' booms, Hall et al. (2011: 839) write 'the basic tenure relations that 
existed before the boom survive it. In such cases, the most obvious power shaping land control during the boom is thus market power, as newly-valuable land changes hands through mutually-agreed sales and leases.'

Hall et al. (2011:841) differentiate four main actors that take part in crop booms. These include: 1) state actors; 2) private companies; 3 ) in situ smallholders; and 4) migrant would-be smallholders. While the various boom crops have been grown under many organizational frameworks, and while smallholders have successfully grown all of them, there is a fairly clear distinction between crops dominated by relatively independent smallholders (cocoa and coffee) and those where larger-scale production has been the rule (fast-growing trees and oil palm), with shrimp and rubber as intermediate cases (Hall et al. 2011).

\section{Materials and Methods}

We mapped land-cover dynamics in MSEA using the MODIS MOD13Q1 product. This product provides MODIS bands and vegetation indices (e.g. Enhanced Vegetation Index (EVI)) with circa $231 \mathrm{~m}$ resolution as 16-day image composites by performing a pixel-based selection of the best observation acquired in the preceding 16 days of the sensors daily image acquisitions (USGS, 2017). This composition approach improves the data substantially by minimizing noise related to cloud cover, haze, etc. in the time-series. Previous studies focusing on land-cover dynamics in MSEA used EVI time-series to identify specific land-use processes or crops (e.g. shifting cultivation, rubber) and more recent studies, focusing on a broader range of dynamics and processes to determine vegetation and land-use phenology, have emphasized the importance of including band 7 (Shortwave Infrared (SWIR)) to improve the mapping accuracy of forest 
dynamics (Grogan, Pflugmacher, Hostert, Verbesselt, \& Fensholt, 2016; Hurni, Hett, Heinimann, Messerli, \& Wiesmann, 2013; Z. Li \& Fox, 2012; Suepa et al., 2016). In this study we consequently used the EVI and the SWIR band (band 7) of the MOD13Q1 product and included the full time-series of 16-day image composites from 2001 through 2014. Despite the image composition strategy our data still showed spikes, especially during the period May to September due to the persistent cloud cover that exists during the rainy season; even in a 16 day period it is not always possible to obtain a clear and noise-free observation. To improve the quality and consistency of the time-series, we thus processed the data with a smoothing algorithm using Timesat software (Eklundh \& Jönsson, 2010; Jönsson \& Eklundh, 2004). Timesat applies a smoothing function to the data and returns files that contain even renditions of the original data. We applied the double logistic function to smoothen the data as it showed the best performance and was recommended by other authors dealing with noisy data (Beck, Atzberger, Høgda, Johansen, \& Skidmore, 2006; Eklundh \& Jönsson, 2010; Hird \& McDermid, 2009). We applied this fitting function to the EVI and SWIR bands covering the area of MSEA from 2001 through 2014. Finally, we rescaled the SWIR and EVI time series to improve classification accuracies by cutting off the top and bottom one percentile, linearly redistributing the remaining values between zero and one, and assigning the bottom and top one percentile a value of zero and one, respectively (van der Linden et al., 2015).

We performed the classification of the full MODIS EVI and SWIR time-series from 2001-2014 using the random forest (RF) classifier implemented in EnMap-Box (Jakimow et al., 2015; van der Linden et al., 2015). Random forests are a machine learning algorithm, which provides substantially higher classification accuracies in contexts with complex ecological issues (Cutler et al., 2007; Schneider, 2012). In contrast to traditional classifiers, e.g. maximum likelihood, it 
manages noise, handles non-linear relationships occurring in the remote sensing data, and makes no assumptions on data distribution (Clark, Aide, Grau, \& Riner, 2010). Furthermore, it requires few user-defined parameters and its computational efficiency makes it suitable for a classification of large datasets (Jakimow et al., 2015; Pal, 2005). Random forests consist of an ensemble of decision-tree classifiers and each tree provides a vote on the most popular class assigned to the input vector (Breiman, 2001). The training dataset for each tree consist of a random subset of the overall data (sampled with replacement). The decision at each node of the tree uses a randomly selected subset of candidate classification features (i.e. the MODIS bands), whereby the number of features is constant and user defined. We set it to the square root of all features, which has been shown to provide a good compromise between predictive accuracy and overfitting (Breiman, 2001). At each node, an optimization is carried out that results in the most homogeneous split of the data (Rodriguez-Galiano \& Chica-Rivas, 2014). To assess the impurity of a split we used the Gini index, and each tree is fully grown until a further subdivision does not reduce the Gini index (Cutler et al., 2007; Jakimow et al., 2015). The out-of-bag observations (i.e. the samples not included in the bootstrap sample) are then used to vote for the most frequent class within each tree and a simple majority vote over all trees provides the final classification (Breiman, 2001; Cutler et al., 2007). We used a maximum of 100 ensemble decision trees to classify the data after testing the influence of the number of decision trees on the overall accuracy by using $90 \%$ of the points for training and $10 \%$ of the points for testing. The inclusion of a larger number of trees (we used 100, 500, 1,000, and 10,000 decision trees) did not improve classification accuracies (we obtained overall accuracies of $83.33 \%, 82.46 \%, 82.16 \%$, and $82.6 \%$ respectively) (Jakimow et al., 2015; Pal, 2005).

We classified the MODIS time-series following an 'upscaling' approach and extracted training 
and verification points from seven Landsat-based land-cover change classifications in the region (Hurni et al. 2017). Due to the differences in pixel sizes, this operation is usually performed by defining a threshold of a majority cover of the 30m resolution land-cover classes within a MODIS pixel (circa 231m resolution), extracting the MODIS pixels that meet the threshold criteria, and classifying the MODIS data with these samples (Clark et al., 2010; DeFries, Townshend, \& Hansen, 1999; Hurni et al., 2013). We adapted this approach and determined the classification scheme and the number of classification samples for an accurate classification of land-cover dynamics in iterations. As shown in Figure 1 (A), we started this process with the extraction of classification samples from the Landsat classifications of land-cover change for seven selected footprints in MSEA.

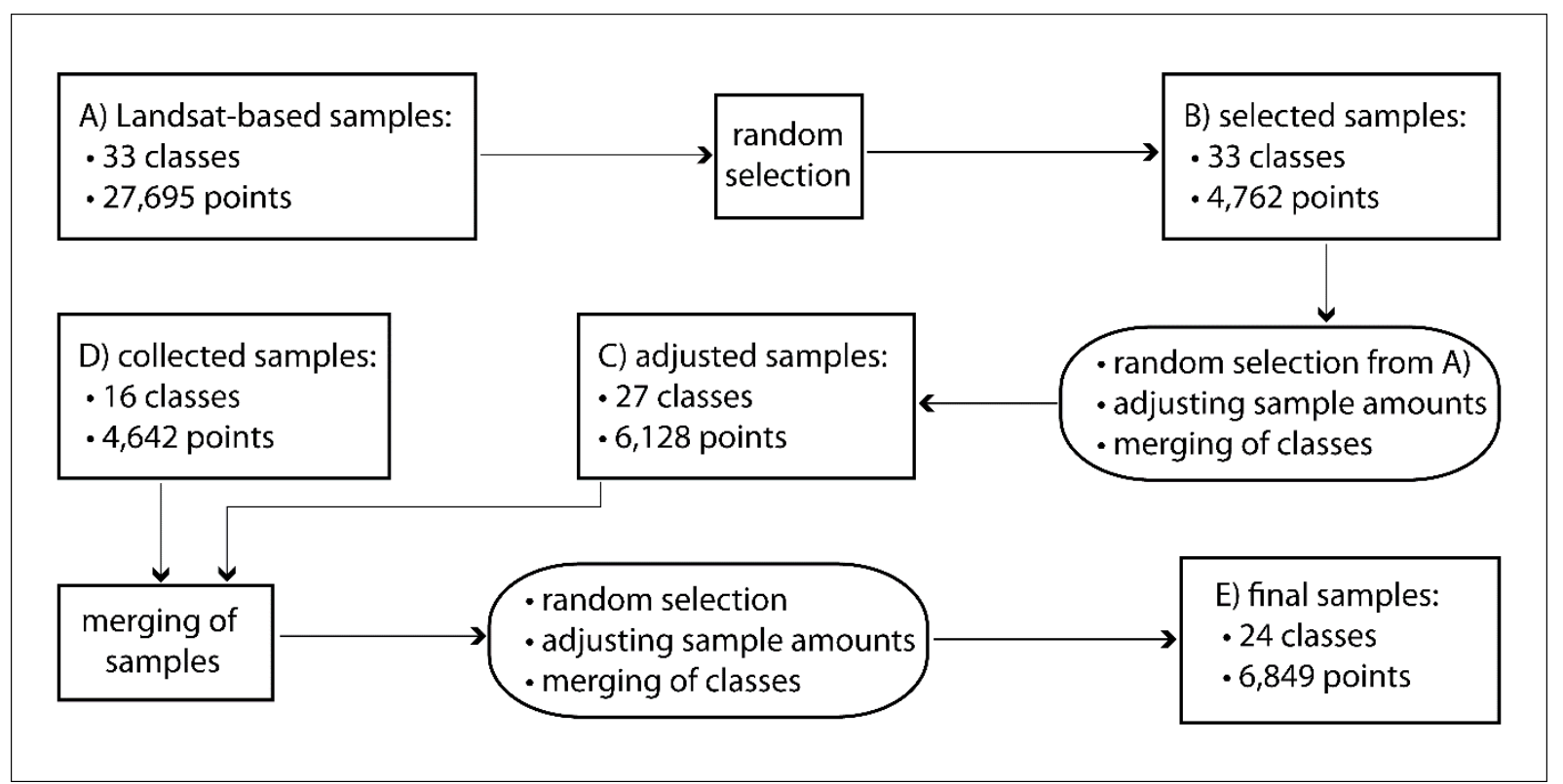

Figure 1: Overview of the classification samples collection approach. Rounded boxes represent classification iterations where we increased accuracies by adjusting sample amounts and merging classes 
Working within these 7 scenes we selected only 'pure' pixels (i.e. the MODIS pixel is fully covered by one Landsat-based land-cover change class) because initial tests that included mixed samples resulted in lower accuracies. This provided samples on three types of land-cover and land-cover change classes: group 1) no-change classes (i.e. evergreen and deciduous forests, low vegetation areas (LVA), water, and tree plantations established before 2003); group 2) boom crop change classes (i.e. rubber, cashews, eucalyptus, coffee, sugarcane) that are subdivided into from-to change (i.e. from evergreen forests, deciduous forests, or LVA to the boom crop) and the period the change occurred (2003-2005, 2006-2008, 2009-2011, 2012-2014); and group 3) landcover change classes without a focus on the date of the change due to the heterogeneity of the timing of change (i.e. rotational agriculture, expansion of LVA, and new water bodies). Next, we validated these samples using Google Earth high-resolution data to avoid the inclusion of classification errors of the Landsat data in the MODIS classification. We obtained 27,695 samples for a total of 33 classes, but their distribution among the classes varied significantly. Due to the difference between the MODIS and Landsat pixel size, we extracted relatively fewer sample points for the more fragmented classes in relation to their area. We obtained an abundance of sample points for the no-change classes (group 1 above); while few samples were obtained for groups 2 and 3. We needed to adjust for this imbalance of sample points across the classes. Various scholars have shown that the appropriate amount of sample points for an accurate supervised classification of land-cover change does not only depend on the class area (spatial heterogeneity), but also on the temporal heterogeneity and the classification scheme (spectral-temporal similarity of classes) (Foody \& Arora, 1997; Heydari \& Mountrakis, 2018; Hurni et al., 2017). To represent temporal heterogeneity, change classes consequently need relatively more sample points despite the small areas they cover. We performed these 
adjustments to the sample points in iterations and started with an adjusted random selection of points based on class area shares (Figure 1 (B)). Due to the large amounts of samples and the imbalanced distribution across classes, we limited the maximum number of points for the largest class to 1,000 points and the minimum number of points to 100 and randomly selected samples for each class within this range based on the class area. In this way we obtained sufficient points for the small change classes to represent the temporal heterogeneity while the larger, usually spatially more heterogeneous classes, also obtained more points. Classes with fewer than 100 samples in total were still included in the classification. In the following classification iterations we focused on class-wise accuracies by using $75 \%$ of the samples for classification and $25 \%$ for verification. We then adjusted sample amounts for the classes with low accuracies in three ways: 1) by increasing the number of samples if more points were available; 2) by merging classes when we had already used all sample points and accuracies were still insufficient. This grouping only affected change classes and was done by crop type, e.g. conversions to cashews in different periods needed to be merged into one cashew class to obtain acceptable accuracies; and 3) by reducing the number of points for classes with large sample sizes (usually the no-change classes); most of the confusions occurred within the classes with few samples (usually the change classes). We selected samples randomly from our pool of all samples for each classification and we continued reiterations until further adjustments to the number of sample points and the classification scheme did not result in higher accuracies in terms of trade-offs among classes and the overall accuracy (Figure $1(\mathrm{C})$ ). Next, we focused on the upscaling, i.e. the performance of the classification outside the seven Landsat footprints. We used multitemporal Google Earth high resolution images to identify locations and classes with upscaling difficulties and added sample points for those locations (Figure 1(D)). This was also guided by 
the authors' knowlege of the study area. We focused on locations where the land-cover and landuse as well as environmental conditions differed from the area covered by the Landsat classifications (e.g. Vietnam, southeastern Thailand and the Tonle Sap area in Combodia). The different boom crops can be distinguished in the high resolution images based on the crop spacing in the $\mathrm{x}$ and $\mathrm{y}$ direction, canopy size and structure, and to a certain degree based on the RGB color representation. Figure 2 shows examples of such transformations for the boom crops. In case there were not sufficient historic high resolution images available, we identified the crop type in the recent high resolution image and the timing of the change and the land-cover before the change using Landsat time-series.

\begin{tabular}{|c|c|c|c|c|c|c|}
\hline & Rubber & Cashews & Coffee & Eucalyptus & Sugarcane & Fruit trees \\
\hline 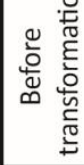 & & & & & 10 & i. \\
\hline 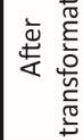 & & $x$ & & & & \\
\hline
\end{tabular}

Figure 2: Examples of transformations to boom crops using Google Earth high resolution images. Different boom crop types can be distinguished based on crop spacing and canopy size and structure

We limited the sample collection to areas where multi-temporal high resolution images were available and we identified pure pixels by overlaying those areas with polygons representing the MODIS pixel size. In this second round of iterations, we used all these samples (4,642 collected Google Earth samples) and the ones from the previous iteration (6,128 selected Landsat samples). Starting from the number of samples defined in the previous iterations we randomly selected the number of classification samples from our new pool of points. We then performed 
the classification in iterations with adjustments to the sample size as described above until tradeoffs between class-wise and overall accuracies could not be increased. During this process we merged, for example, the eucalyptus classes into the class 'pulp trees', as the fast cycle of planting and harvesting related to pulp wood production did not allow us to distinguish tree types (e.g. eucalyptus from acacia). With this last step of optimizing the number of samples and their spatial distribution, we obtained a total number of 6,849 samples, ranging from 19-918 points per class; we collected 5,126 samples from our Landsat analyses and 1,723 samples from Google Earth (Figure $1(\mathrm{E})$ ). Table 1 shows the classification scheme with a total of 24 classes, six represent permanent land-cover types (group 1) and 18 land-cover change classes. Eleven of the change classes focus on rubber and sugarcane and specify from-to changes and the period of change (group 2), while the seven other change classes (group 3) do not provide information on the 'from' land-cover or the timing of change. This classification scheme does not include all the land-cover changes that occured in the study area. For example it is possible that during our study period forests were converted to one boom crop and then later replaced by another boom crop (multiple transformations). However, our work at the Landsat scale as well as the revision of the MODIS samples showed that such transformations represent only a small share of the study area compared with single transformations, e.g. forests to boom crops (Hurni et al., 2017). As a result it was not possible to obtain sufficient sample points for areas with multiple transformations. The classification scheme we applied thus brings a certain generalization and only focuses on the prevailing land-cover transformations in the study area. 
Table 1: The classification scheme applied to MODIS time-series for unchanged and changed land-cover types. We only included classes highlighted in the shaded cells due to absence of some classes during certain periods.

\begin{tabular}{|c|c|c|c|c|}
\hline & 2003-2005 & 2006-2008 & 2009-2011 & 2012-2014 \\
\hline $\begin{array}{l}\text { Land-cover } \\
\text { classes } \\
\text { (group 1) }\end{array}$ & & $\begin{array}{r}\text { Evergre } \\
\text { Deciduou } \\
\text { Low vegeta } \\
\mathrm{R} \\
\text { Pir }\end{array}$ & $\begin{array}{l}\text { r } \\
\text { rests (F) } \\
\text { ests (DF) } \\
\text { areas (LVA) } \\
\text { or } \\
\text { ole }\end{array}$ & \\
\hline \multirow{5}{*}{$\begin{array}{l}\text { Detailed } \\
\text { land-cover } \\
\text { change } \\
\text { (group 2) }\end{array}$} & Rubber from $\mathrm{F}$ & Rubber from $\mathrm{F}$ & Rubber from $\mathrm{F}$ & \multirow{5}{*}{$\begin{array}{c}\text { Rubber from F } \\
\text { Rubber from DF } \\
\text { Rubber from LVA } \\
\text { Sugarcane from F } \\
\text { Sugarcane from DF }\end{array}$} \\
\hline & Rubber from DF & Rubber from DF & Rubber from DF & \\
\hline & Rubber from LVA & Rubber from LVA & Rubber from LVA & \\
\hline & \multirow{2}{*}{$\begin{array}{c}\text { Sugarcane from F } \\
\text { Sugarcane from DF }\end{array}$} & Sugarcane from $\mathrm{F}$ & Sugarcane from F & \\
\hline & & Sugarcane from DF & Sugarcane from DF & \\
\hline $\begin{array}{c}\text { Land-cover } \\
\text { change } \\
\text { (group 3) }\end{array}$ & \multicolumn{4}{|c|}{$\begin{array}{c}\text { Rotational agriculture } \\
\text { Expansion of low vegetation areas / Intensification } \\
\text { New hydropower dams } \\
\text { Pulp trees } \\
\text { Cashews } \\
\text { Fruit trees } \\
\text { Coffee }\end{array}$} \\
\hline
\end{tabular}

We performed a ten-fold cross-validation using the 6,849 sample points to validate the classification (Kohavi, 1995). This approach split the sample points into ten equally-sized parts and used nine parts to train the classifier and the remaining part to assess the accuracy of the classification. We repeated this ten times so that each part is used once for the evaluation of the classification accuracy and the final accuracy of the map is derived by calculating the arithmetic mean of all ten accuracy assessments. The ten-fold cross-validation is considered to be more reliable than traditional approaches that split the sample points into a single training and validation set, because both, the final accuracy assessment and classification, are based on all sample points, but are still independent. This approach improves classification accuracies as potential biases between the training and validation points are avoided. Furthermore we evaluated the accuracy of mixed pixels as at the MODIS scale, land-cover dynamics often occur at the sub-pixel level (Lunetta, Knight, Ediriwickrema, Lyon, \& Worthy, 2006; Setiawan \& 
Yoshino, 2014). We selected mixed pixels from areas covered by the Landsat classifications (7 footprints across MSEA) and extracted all pixels that showed a majority land-cover of 70-80\% and of 50-60\% within the MODIS pixels to evaluate how different shares of majority cover affected the classification accuracy. From these two sets of mixed pixels we then randomly selected the same number of samples as we used for the classification with the pure pixels so that we conducted three accuracy assessments (pure pixels, mixed pixels with 70-80\% majority cover, and mixed pixels with 50-60\% majority cover) based on the same number of validation points. For pulp trees, coffee, and sugarcane we were not able to extract the targeted amount of mixed pixels from the Landsat classifications. In the sugarcane classes the number of mixed validation pixels was very low so that accuracy estimates may have been affected. Given this limitation error adjusted area estimates were calculated according to the approach suggested by Olofsson et al. (2014) using the accuracy assessment of pure pixels only. For each class we then calculated the ratio between the area defined by the pixels and the error adjusted area estimate. These ratios for each class were then used to obtain error adjusted area estimates for each country / region.

\section{Results}

Figure 3 outlines the study area. It includes all of Laos and Cambodia, most of Vietnam (except north of Hanoi), northeastern Thailand and the rubber growing area southeast of Bangkok, Shan State in Myanmar, and Xishuangbanna Prefecture in southern Yunnan, China. The classification consists of 24 classes and 16 classes represent boom crops. Pulp trees, coffee, cashews, fruit trees, and pineapple are each represented by one class; while for rubber we mapped ten classes and sugarcane two classes showing from-to changes and the period of change. For visualization purposes we combined the different rubber and sugarcane classes into one rubber and one 
sugarcane class (Fig. 3); Figure 4 shows an extent of the map with the full classification scheme and Figure A (supplementary material) shows the expansion of rubber around Stung Treng, Cambodia.

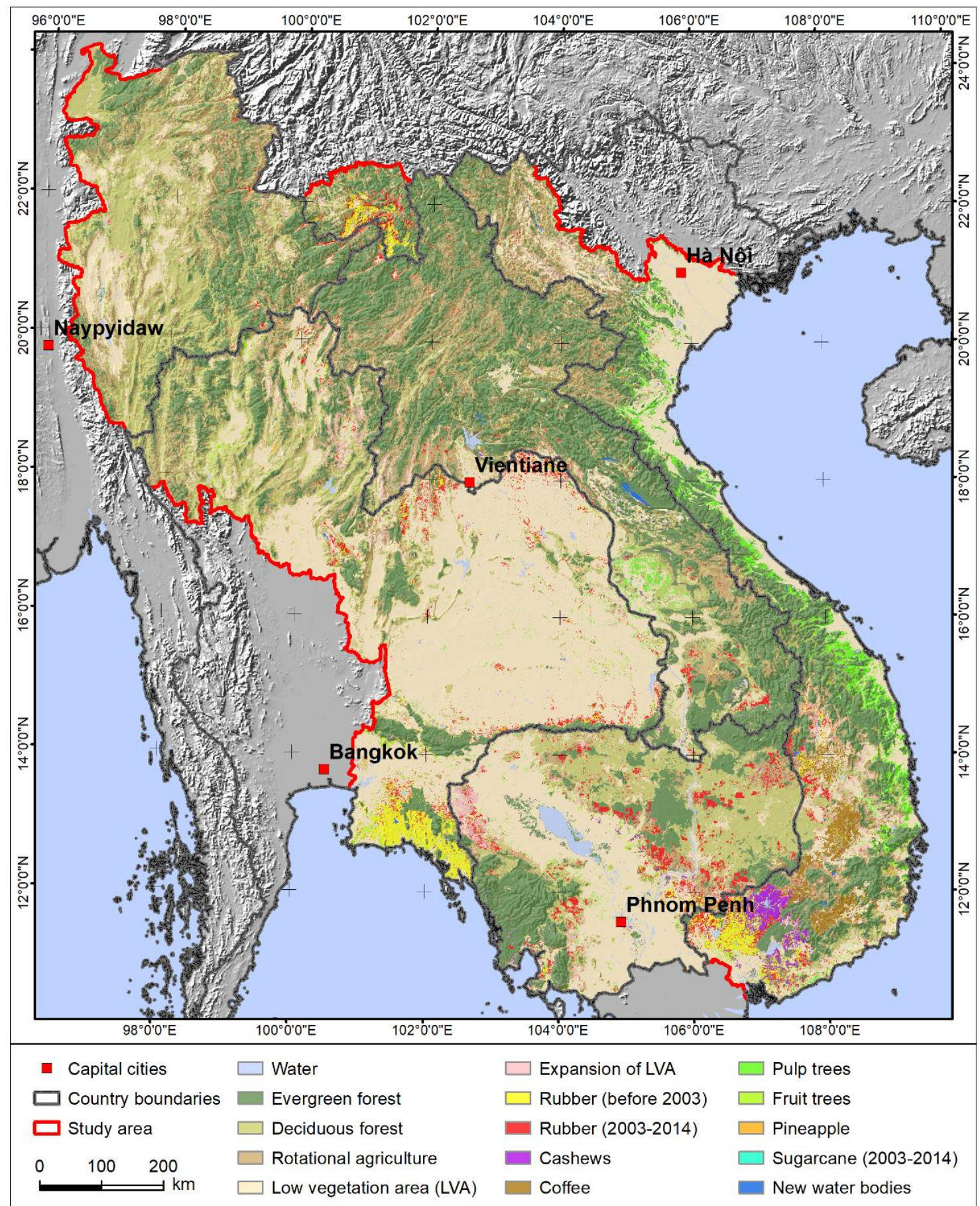

Figure 3: Land-cover change classification of Mainland Southeast Asia (MSEA). Change trajectories to rubber and sugarcane were grouped into one class. 


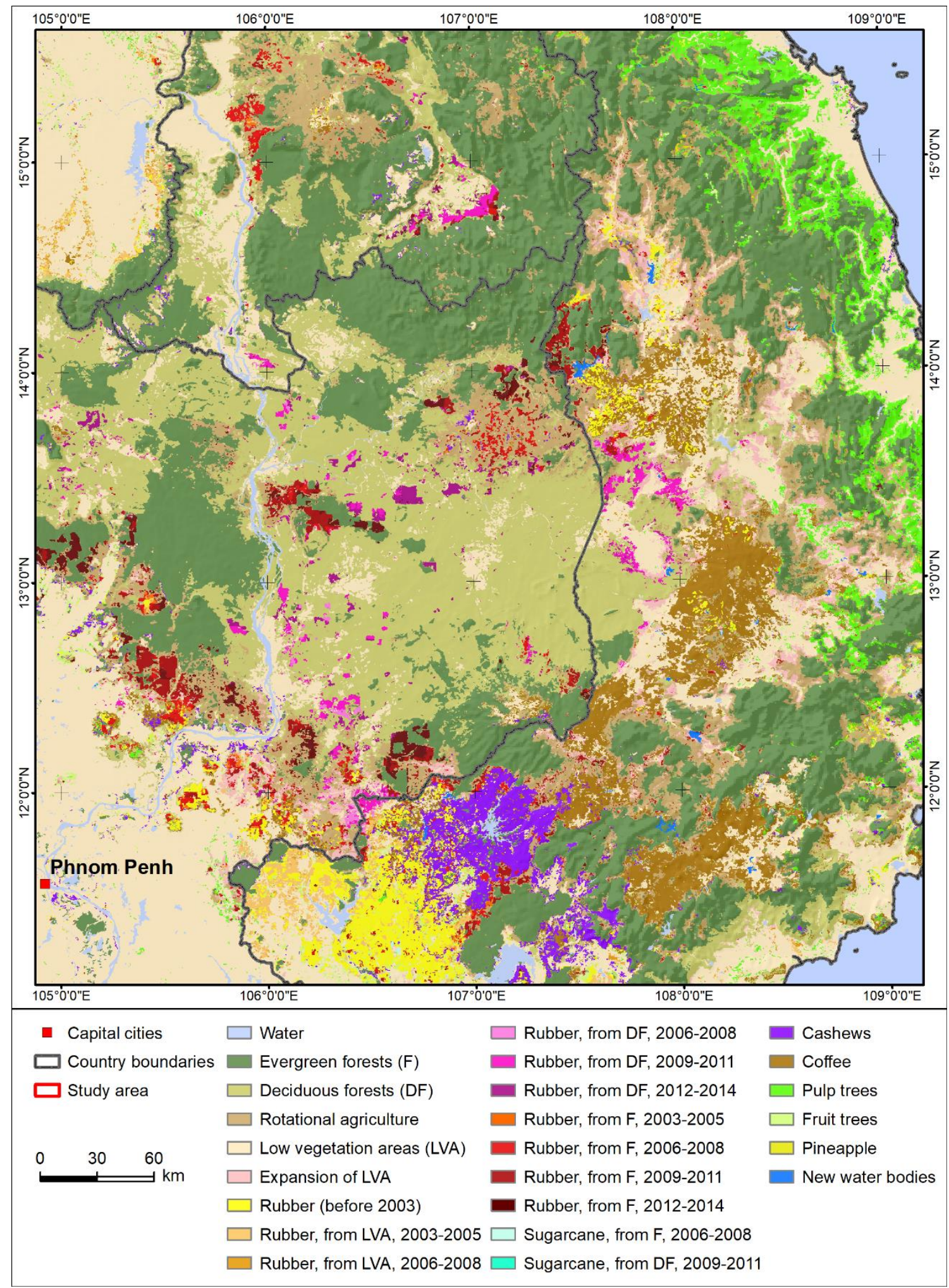

Figure 4: A selected extent of the land-cover change classification showing southern Laos, northeastern Cambodia, and the Central Highlands of Vietnam. Cambodia and Laos show mainly new rubber while in Vietnam old and new rubber as well as cashew, coffee, and pulp tree plantations occur. 
The ten-fold cross validation resulted in an overall accuracy of the classification of $82.2 \%$ and only four of the classes (highlighted in table 2) show either user's or producer's accuracies (UA and PA) below 70\%. High accuracies were obtained across all three groups of classes; classes with lower UA and PA only occurred in the change classes (groups 2 and 3) and prevailed in group 3, where we did not consider the timing of the change. The no-change classes (group 1) performed well and confusion was limited to the rotational agriculture class, but also some of the boom crops (e.g. pulp and fruit trees). Classes of group 2, which specify from-to changes and the period of change, performed well with only a few misclassifications occurring within rotational agriculture (mainly classes 'rubber from forests $(\mathrm{F})$ '), low vegetation areas 'rubber from LVA'), and deciduous forests 'rubber from DF'). Only the class 'rubber from LVA, 2006-2008' showed a UA or PA $<70 \%$ due to confusions with the class 'LVA' and to a certain degree with 'rubber from F, 2006-2008'. The class 'rubber from LVA, 2006-2008' mainly occurred in Thailand where rubber was planted by smallholders. Due to the fragmentation of this class, we were able to obtain relatively few samples when compared to the size of the class area. Most likely, the temporal heterogeneity could not be represented sufficiently with these samples, which led to misclassifications either with 'LVA' (similar dynamics up to 2010 due to the weak signal of young rubber) or 'rubber from F, 2006-2008' (the same signal for rubber regrowth from 20062014). Interestingly this did not occur for the class 'rubber from LVA, 2003-2005', which also occurs mainly in Thailand on fragmented plots. We used the same number of sample points for the corresponding class 'rubber from F, 2003-2005', which probably reduced misclassifications between the two classes. Similar effects have been observed by Hurni et al. (2017) where errors between classes that represented similar dynamics tended to increase when there was an imbalance among the number of sample points. Confusions with the class 'LVA' most likely 
occurred because of the early conversion to rubber. With developed canopies, the signal was clear and no misclassifications with 'LVA' occurred. Most of the change classes in group 2 show high accuracies and usually the UA was bigger than the PA. Our area estimates on the expansion of boom crops can thus be considered as reliable, but we tend to slightly underestimate their expansion.

Temporally heterogeneous classes of group 3 (e.g. rotational agriculture, expansion of LVA, fruit trees, cashews, pulp trees) performed well, but tended to show lower accuracies.

Misclassifications mainly occurred within the classes of group 3 and with forests. The area of rotational agriculture is slightly overestimated and includes forested areas, 'expansion of LVA', and few pixels of boom crop classes. Conversions to low vegetation areas ('expansion of LVA') were underestimated due to confusions with rotational agriculture, LVA, and pulp trees. Similarly fruit trees were labelled as rotational agriculture, LVA, or forests, which led to an underestimation of the area of this class. Many of these changes occurred in forested areas; a forest clear-cut is a stronger signal compared to crop or fallow regrowth, which looks similar for most crops/fallow in the first couple of years due to small canopies, intercropping, and weeds (Chen et al., 2012; Z. Li \& Fox, 2011, 2012). Confusions can thus easily occur because all of these classes show some form of forest clear-cutting followed by regrowth throughout the study period. We assume that accuracies could be improved by dividing these classes into multiple classes based on periods of change, but in the study at hand this was not possible. Change dynamics of certain classes are too heterogeneous for a subdivision, which concerns e.g. rotational agriculture with a myriad of crop-fallow rotation lengths across the region, or pulp trees where planting and harvesting occurs within a couple of years. On the other hand, some fragmented classes cover rather small areas and sufficient samples for a reliable classification 
could only be obtained by grouping the periods of change, as was the case for e.g. cashews and coffee. For less fragmented classes like 'sugarcane from DF, 2009-2011', we achieved high accuracies with as few as 19 samples. However, sugarcane shows a cropping cycle of 12-18 months, different from all the other crops. We assume that this clear signal, which differs from the signal of all the other classes, also allowed for a more accurate classification with only few points.

The accuracy assessment using mixed pixels showed that misclassifications tend to increase for MODIS pixels that represent more than one land-cover or land-cover change class. For pure pixels we obtained an overall accuracy of $82.2 \%$; for pixels with a majority cover of one landcover or land-cover change class of $70-80 \%$ we obtained an accuracy of $61.5 \%$; and for pixels with a majority cover of 50-60\% we obtain an accuracy of $43.4 \%$ (see Table A, supplementary material). In mixed pixels we also observe misclassification patterns, but which specific classes were confused was less clear than the evaluation using pure pixels. There are not only more misclassifications, but confusions also involve more classes. Nevertheless, certain characteristics can be observed as we move from the evaluation of pure pixels towards the evaluation of increasingly mixed pixels. In group 1, the classes 'water', 'rubber (before 2003)', and 'pineapple' show a high accuracy for pure pixels and UA's are higher than PA's. For the mixed pixels UA's remain high but PA's decrease rapidly and the area of these classes is thus underestimated. Among mixed pixels water is often classified as LVA, probably due to the large amounts of paddy fields that are seasonally covered by water and are included in the class LVA. 'Rubber (before 2003)' is confused with LVA, rotational agriculture, orchards, coffee, and earlier conversions to rubber while 'pineapple' is confused with LVA and fruit trees. These classes often occur next to each other, which resulted in a large number of misclassifications in 
mixed pixels. Evergreen forests (mainly mixing with rotational agriculture), LVA (mainly mixing with deciduous forests), and deciduous forests (mainly mixing with LVA and rotational agriculture) show a decrease in both, UA and PA. In mixed pixels we underestimate the area of evergreen forests (UA > PA) while we overestimate the area of LVA and deciduous forests. Classes from group 2 (conversions to rubber and sugarcane) show similar patterns of misclassifications for mixed pixels as for the pure pixels. UA's tend to be higher than PA's, but with increasingly mixed pixels both are lower and the difference between UA and PA increases. Among both pure and mixed pixels we thus tend to underestimate the area of these classes. Confusions mainly occur in the class 'rotational agriculture' (conversions from forests to boom crops), the class LVA (conversions from LVA to boom crops), and to a certain degree among classes that show the same transformation type (e.g. forests to boom crops), but a different timing of change. For the sugarcane classes only a few mixed pixel were available for validation and a comparison with the evaluation using pure pixels was not possible. Classes in group 3 tend to show lower accuracies for the mixed pixels and only the class 'new water' retained a high UA for increasingly mixed pixels, but similar to the class 'water' the PA is substantially lower. For the other classes the relationship between UA and PA remains mostly the same, but accuracies decline with increasingly mixed pixels and misclassifications mainly occur with forests, rotational agriculture, and LVA. In mixed pixels e thus tend to underestimate the area covered by land-cover conversions (groups 2 and 3) while we overestimate the area covered by the classes deciduous forests, LVA, and rotational agriculture. 
Table 2: Accuracy assessment based on a ten-fold cross-validation of the land-cover change classification (overall accuracy: $82.2 \%$ ). Highlighted rows show a user or producer accuracy below $70 \%$. Area estimates are error adjusted.

\begin{tabular}{lccrrr} 
Land-cover (change) class & UA & PA & Area $\left.\mathbf{( k m}^{\mathbf{2}}\right)$ & Area $(\boldsymbol{\%})$ & Samples \\
\hline Water & 96.0 & 95.0 & $18,627.6$ & 1.62 & 300 \\
Evergreen forests (F) & 83.0 & 89.4 & $289,189.9$ & 25.08 & 918 \\
Deciduous forests (DF) & 82.2 & 87.5 & $158,128.0$ & 13.71 & 569 \\
Low vegetation areas (LVA) & 77.9 & 90.2 & $281,789.8$ & 24.44 & 735 \\
Rubber (before 2003) & 86.9 & 83.5 & $19,321.6$ & 1.68 & 256 \\
Pineapple & 97.9 & 93.9 & $2,530.5$ & 0.22 & 100 \\
\hline Rubber, from F, 2003-2005 & 95.2 & 79.0 & $2,294.0$ & 0.20 & 100 \\
Rubber, from LVA, 2003-2005 & 79.2 & 77.6 & $7,256.3$ & 0.63 & 100 \\
Rubber, from F, 2006-2008 & 85.6 & 88.3 & $11,534.2$ & 1.00 & 350 \\
Rubber, from DF, 2006-2008 & 92.2 & 71.0 & $2,687.4$ & 0.23 & 100 \\
Rubber, from LVA, 2006-2008 & 85.1 & 65.5 & $15,313.3$ & 1.33 & 150 \\
Rubber, from F, 2009-2011 & 87.1 & 79.1 & $14,099.3$ & 1.22 & 360 \\
Rubber, from DF, 2009-2011 & 89.9 & 83.7 & $7,477.4$ & 0.65 & 202 \\
Rubber, from F, 2012-2014 & 89.2 & 71.8 & $9,750.1$ & 0.85 & 150 \\
Rubber, from DF, 2012-2014 & 81.8 & 81.0 & $4,550.9$ & 0.39 & 100 \\
Sugarcane, from F, 2006-2008 & 100.0 & 97.9 & 527.0 & 0.05 & 100 \\
Sugarcane, from DF, 2009-2011 & 100.0 & 89.5 & 484.1 & 0.04 & 19 \\
\hline Rotational Agriculture & 62.5 & 70.4 & $155,287.2$ & 13.47 & 706 \\
Expansion of LVA / intensification & 80.7 & 67.2 & $42,306.8$ & 3.67 & 356 \\
New Water & 100.0 & 91.9 & $2,379.6$ & 0.21 & 100 \\
Pulp trees & 78.2 & 74.7 & $44,829.3$ & 3.89 & 400 \\
Cashews & 92.7 & 74.5 & $14,715.7$ & 1.3 & 156 \\
Fruit trees & 84.5 & 68.0 & $28,487.9$ & 2.47 & 202 \\
Coffee & 87.5 & 88.9 & $19,532.9$ & 1.69 & 320 \\
\hline
\end{tabular}

As shown in table 3 we found that in $2014,25 \%$ of the landscape was covered by evergreen forest, $14 \%$ by deciduous forest, $13 \%$ by rotational agriculture, and $24 \%$ by low vegetation areas (mainly cereal crops but also scrub and bushes). In terms of tree crops we found that $8 \%$ of the landscape had been converted to rubber; while cashews covered $1 \%$ of the landscape, coffee and fruit trees each covered about $2 \%$, and pulp trees covered $4 \%$. Considered as a single category, tree crops accounted for $18 \%$ of the landscape. Looking only at rubber, the largest boom crop in the region, approximately $74,960 \mathrm{~km}^{2}$ of land were converted to rubber between 2003 and 2014; $50 \%$ of this was planted on former evergreen forest land and $20 \%$ on deciduous forest land 
(Table 4). Hence $70 \%$ of the expansion of rubber plantations caused deforestation. Thirty percent of the rubber expansion occurred on areas previously covered by low vegetation (mainly annual crops). Our hypothesis that boom crops were marked by intensification of previously used agricultural land and was not necessarily accompanied by deforestation was wrong. The expansion of rubber between 2003 and 2014 caused deforestation primarily in Cambodia and Laos, but also in Vietnam, Xishaungbanna, and Shan State as well.

Table 3: Land-cover in the selected regions of 6 countries in 2014.

Land-cover in 2014 (area in $\mathrm{km}^{2}$, and \% total by country)

\begin{tabular}{lrrrrrrr}
\hline Land Cover & Thailand & Cambodia & Vietnam & $\begin{array}{c}\text { Xishuang- } \\
\text { banna, China }\end{array}$ & Laos & $\begin{array}{c}\text { Shan State, } \\
\text { Myanmar }\end{array}$ & Total \\
\hline Evergreen & 37,967 & 35,437 & 59,649 & 7,443 & 108,790 & 39,837 & 289,124 \\
Forests & 12 & 18 & 24 & 35 & 50 & 26 & 25 \\
\hline Deciduous & 39,786 & 39,522 & 9,645 & 1,578 & 15,459 & 52,087 & 158,077 \\
Forests & 13 & 20 & 4 & 7 & 7 & 33 & 14 \\
\hline Rotational & 24,807 & 10,877 & 29,264 & 3,533 & 51,383 & 35,397 & 155,261 \\
Agriculture & 8 & 6 & 12 & 17 & 24 & 23 & 13 \\
\hline Low Veg & 146,627 & 49,691 & 47,888 & 855 & 17,050 & 19,602 & 281,712 \\
Area & 46 & 26 & 19 & 4 & 8 & 13 & 24 \\
\hline & 28,614 & 29,743 & 19,166 & 6,182 & 7,656 & 2,921 & 94,282 \\
Rubber & 9 & 15 & 8 & 29 & 4 & 2 & 8 \\
\hline Cashews & 1,475 & 2,530 & 8,879 & 62 & 1,640 & 127 & 14,713 \\
\hline Coffee & 0 & 1 & 4 & 0 & 1 & 0 & 1 \\
\hline Pulp Trees & 1,379 & 1,088 & 15,654 & 305 & 468 & 636 & 19,530 \\
\hline Fruit Trees & 0 & 1 & 6 & 1 & 0 & 0 & 2 \\
\hline All Tree & 4,387 & 3,059 & 31,589 & 83 & 5,483 & 227 & 44,828 \\
Crops & 1 & 2 & 13 & 0 & 3 & 0 & 4 \\
\hline & 51,634 & 3,018 & 5,678 & 724 & 2,776 & 652 & 28,481 \\
& 5 & 2 & 2 & 3 & 1 & 0 & 2 \\
\hline
\end{tabular}

Land-cover changes related to boom crops vary heavily between, but also within the countries of MSEA. This concerns the type of boom crops, the timing of the conversion, the land-cover type before the conversion, and plantation patterns / types (e.g. small scale vs. concessions). We 
considered two external factors affecting rubber expansion, national land policies and the market price of rubber. Table 4 shows the type of land-cover that rubber replaced; Table 5 summarizes rubber expansion in 4 time periods between 2003 and 2014. Figure 5 shows rubber prices through time. Prices were relatively stable between 1978 and 2003; after that they rose steadily until the economic crisis of 2008 when they fell steeply; after 2008 rubber prices rose again through 2011 when the European economic debt crises led to a downturn in commodity prices. In 2017 rubber prices are roughly equivalent to what they were in 2005. We will explore these changes on a country by country basis.

Table 4: Land converted to rubber by country (area in $\mathrm{km}^{2}$, and \% total)

\begin{tabular}{lrrrrrrr}
\multicolumn{1}{c}{ Land Cover } & Thailand & Cambodia & Vietnam & $\begin{array}{c}\text { Xishuang- } \\
\text { banna, China }\end{array}$ & Laos & $\begin{array}{c}\text { Shan State, } \\
\text { Myanmar }\end{array}$ & Total \\
\hline Rubber from evergreen & 1,646 & 17,624 & 7,240 & 3,238 & 6,012 & 1,918 & 37,677 \\
forests & 9 & 61 & 55 & 84 & 82 & 67 & 50 \\
\hline Rubber from deciduous & 313 & 10,456 & 2,253 & 29 & 1,075 & 588 & 14,715 \\
forests & 2 & 36 & 17 & 1 & 15 & 21 & 20 \\
\hline Rubber from low & 16,956 & 659 & 3,788 & 602 & 204 & 360 & 22,568 \\
vegetation area & 90 & 2 & 29 & 16 & 3 & 13 & 30 \\
\hline Rubber from evergreen & 1,959 & 28,080 & 9,493 & 3,266 & 7,087 & 2,506 & 52,392 \\
and deciduous forests & 4 & 54 & 18 & 6 & 14 & 5 & 100 \\
\hline
\end{tabular}

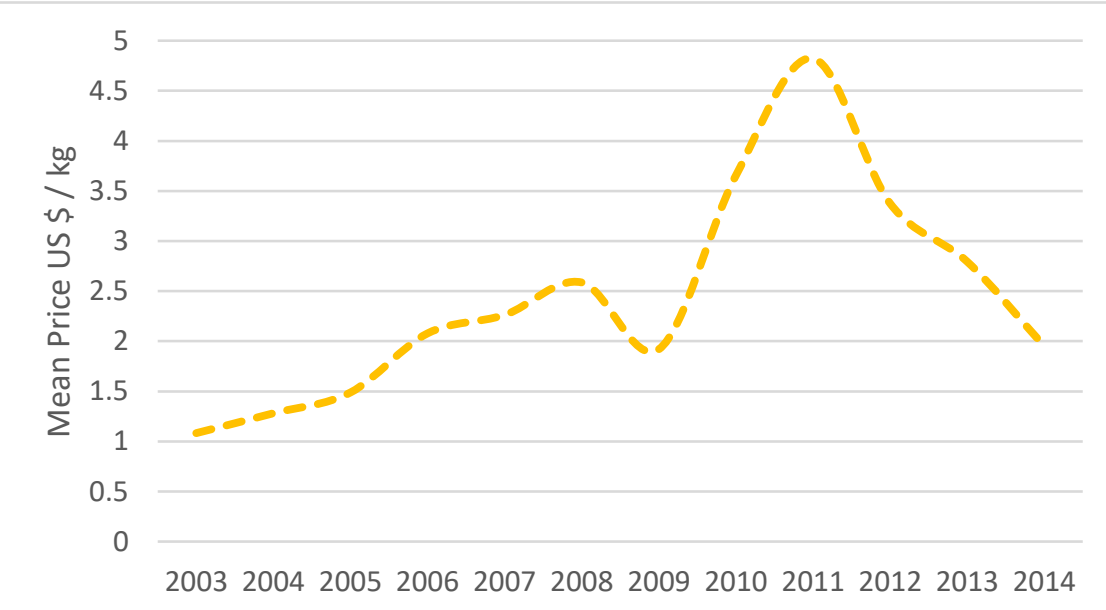

Figure 5: Mean rubber price US Dollar/kg per year (“IndexMundi,” 2017). 


\section{Thailand}

Thailand shows old rubber (pre 2003, mainly occurring southeast of Bangkok on large scale plantations); this accounted for $34 \%$ of the rubber we mapped in Thailand. New rubber was planted in northeast Thailand between 2003 and 2008 by small farmers converting permanent agriculture to rubber; $90 \%$ of the rubber planted after 2003 was on areas mapped as low vegetation (crops); only $4 \%$ of deforestation caused by rubber in the region occurred in Thailand (Fig 3, Tables 2 and 3). After the 2008 economic crises, farmers in the Northeast stopped planting rubber. In northern Thailand smallholder planted fruit trees (Fig 3 and Table 1). It should be noted that while the expansion of rubber in northeast Thailand did not cause deforestation, this is because the Northeast was heavily deforested in the 1950 and 60 s as the Thai government encouraged the cultivation of cash crops (Vityakon et al., 2004). It was the land used to grow these crops (rice, cassava, others) that was later converted to rubber.

In the 1970s the Thai government began to introduce rubber in the Northeast as a viable commercial tree crop. The Thai national government supported the development of infrastructure and services such as the Buriram Rubber Research Station and the numerous Offices of Rubber Replanting Aid Fund (ORRAF) found throughout the Northeast. Beginning in 1989 ORRA provided smallholders in the Northeast, those with less than 2.4 ha of land, with technical advice, free seedlings and fertilizer, low-cost credit for labor costs (including family labor), material inputs (especially herbicides), and other income generating activities. After 2004, ORRAF limited its technical advice on cultivation and free seedlings to households with up to 1 to 1.25 ha of land. We assume that these policy changes followed by the economic crisis reduced smallholder incentives to plant rubber and basically stopped rubber expansion. Figure 6 shows the area of rubber expansion in Thailand and the other countries / regions and Figure 5 the 
changes in rubber prices during this period.

Table 5: Expansion of rubber in MSEA by country/region and year (area in $\mathrm{km}^{2}$, and \% total)

\begin{tabular}{lrrrrrrr}
\multicolumn{1}{c}{ Class Names } & Thailand & Cambodia & Vietnam & $\begin{array}{c}\text { Xishuang- } \\
\text { banna, China }\end{array}$ & Laos & Shan State, \\
Myanmar & Total \\
\hline \multirow{2}{*}{ Rubber, before 2003 } & 9,699 & 1,005 & 5,885 & 2,313 & 365 & 55 & 19,322 \\
& 34 & 3 & 31 & 37 & 5 & 2 & 20 \\
\hline \multirow{2}{*}{ Rubber, 2003-2005 } & 5,104 & 667 & 2,521 & 963 & 234 & 61 & 9,550 \\
& 18 & 2 & 13 & 16 & 3 & 2 & 10 \\
\hline \multirow{2}{*}{ Rubber, 2006-2008 } & 13,463 & 4,456 & 3,763 & 2,793 & 3,256 & 1,802 & 29,533 \\
& 47 & 15 & 20 & 45 & 43 & 62 & 31 \\
\hline \multirow{2}{*}{ Rubber, 2009-2011 } & 271 & 12,502 & 5,713 & 87 & 2,695 & 310 & 21,576 \\
& 1 & 42 & 30 & 1 & 35 & 11 & 23 \\
\multirow{2}{*}{ Rubber, 2012-2014 } & 77 & 11,114 & 1,284 & 26 & 1,106 & 693 & 14,301 \\
& 0 & 37 & 7 & 0 & 14 & 24 & 15 \\
\hline Total & 28,614 & 29,743 & 19,166 & 6,182 & 7,656 & 2,921 & 94,282 \\
\hline \% of total rubber & 30 & 32 & 20 & 7 & 8 & 3 & 100 \\
\hline
\end{tabular}

\section{Cambodia}

In Cambodia, 79\% of the conversion to rubber occurred between 2009 and 2014 (Table 5): and $97 \%$ of this conversion replaced forest lands; $54 \%$ of all deforestation caused by the conversion to rubber in the mapped region occurred in Cambodia (Table 2). Fruit trees, cashews, pulp trees, and coffee also occur, but on fewer and smaller plantations compared to rubber (Fig 4). The 2001 Land Law established a relatively comprehensive legal framework for land tenure and administration and extended 'ownership' rights to residential and agricultural land. The law also formalized a system for granting land concessions for economic purposes such as an agribusiness enterprise (Economic Land Concessions, or ELCs); the law stipulated that ELCs have a maximum duration of 99 years, are limited to 10,000 hectares per concessionaire, and concession land must be put to use within twelve months of being granted (Scurrah \& Hirsch, 2015). All but one of the rubber concessions were granted after 2005 (Open Development Cambodia (ODC), 
2017). In 2012 the government placed a moratorium on the issuing of new ELCs and instructed a review of existing concessions. Figure 6 shows the area of rubber expansion in Cambodia. A small amount of rubber $\left(1,005 \mathrm{~km}^{2}\right)$ had been planted before 2003 , while only $667 \mathrm{~km}^{2}$ was planted between 2003 and 2005. After 2005 both rubber expansion and rubber prices (Figure 5) rose rapidly until 2011. After 2012, further rubber expansion was prohibited by the moratorium, however, companies that had already received their concession continued to plant new rubber in order to meet the requirement that all concession land be utilized. Interviews with officials from three different rubber concessions in the Northeast indicated that given the low rubber prices they were trying to diversify their new plantings with cashews and black pepper. Most of the rubber we mapped in Cambodia was grown on large concessions although some smallholder rubber was also noted.

\section{Vietnam}

In northern and central Vietnam pulp tree plantations prevail while southern Vietnam shows large scale plantations of old and new rubber ( $72 \%$ of the new rubber was planted on forest land; and $18 \%$ of the deforestation caused by rubber in the region was in Vietnam), cashews, and coffee (Fig 3 and Tables 1 and 2). Thirty-one percent of the rubber we mapped in Vietnam was planted before 2003; and 33\% was planted between 2003 and 2008 (Table 5). In 2009 the Prime Minister's Office issued Decision 750/QD-TTg aiming to increase Vietnam's rubber plantation area to $8,000 \mathrm{~km}^{2}$ by 2020 (Akram-Lodhi, 2010)and 37\% of the rubber we mapped was planted after 2009. Today, Gia Lai Province (Central Highlands) has become the key location for rubber plantation expansion with total area accounting for $12 \%$ of the total rubber plantation area of the country; Dak Lak Province (Central Highlands, south of Gia Lai Province) accounts for $4 \%$ of the total rubber plantation area of the country in 2012. Figure 6 shows the area of rubber 
expansion in Vietnam and of the other countries / regions and Figure 5 the changes in rubber prices during this period.

\section{Xishuangbanna Prefecture, Yunnan, China}

Thirty-seven percent of the rubber in Xishuangbanna was planted before 2003 (Table 5); new smallholder plots were established between 2006 and 2008 (85\% were converted from forests; approximately $6 \%$ of the deforestation caused by rubber in the region was in Xishuangbanna) (Fig 3, Tables 2 and 3). In early 1950's China introduced rubber into Xishuangbanna to be grown on large-scale state collective farms. In 1982 China dismantled farming communes and returned land to farmers for growing crops — which included rubber in Xishuangbanna. China strengthened incentives for planting rubber in 2002 with the 'Grain for Green' campaign to promote economic development and stop shifting cultivation. Rubber is considered a 'forest' tree and farmers were subsidized for replacing their shifting cultivation fields with rubber trees (Fox \& Castella, 2013). Figure 6 shows the area of rubber expansion in Xishuangbanna. After the 2008 economic crisis only $113 \mathrm{Km}^{2}$ of rubber were planted.

\section{Laos}

As of 2014 Laos still had 57\% forest cover; most rubber plantations were established after 2006; and $97 \%$ were planted on previously forested land. Laos accounted for $14 \%$ of the deforestation in the region caused by rubber expansion (Tables 1, 2 and 3). In northern Laos rubber is the main boom crop (smallholders and concessions) while in the South large scale plantations of rubber, pulp trees, and sugarcane occur (Figs 3 and 4). The Lao government introduced new land laws in the 1990 s to demarcate forests and protected areas. The 1996 National Land Forest Allocation Policy delineated village boundaries and recognized villages' rights to manage and use 
agricultural land and limited forest resources. A land titling program funded by World Band and Australian Agency for International Development (1998 to 2007) led to the granting of large concessions to companies from neighboring countries. In southern Laos, the largest recipients of land concessions are Vietnamese investors in rubber plantations (Manivong, Cramb, \& Newby, 2014). In 2004 China established the Opium Replacement Program (ORP) to curb opium production. The ORP provided Chinese companies finical and bureaucratic support to invest in large-scale commercial agriculture in northern Laos and Myanmar. Rubber was the main crop established through ORP support. In 2007 Laos placed a moratorium on land concessions and a second moratorium was announced in 2012 (Lu, 2017). A ceiling of $3,000 \mathrm{~km}^{2}$ (nationwide) was placed on rubber; as of 2014 we mapped 7,656 km² of rubber. Figure 6 shows the area of rubber expansion in Laos and of the other countries / regions and Figure 5 the changes in rubber prices during this period. Rubber planting in Laos basically stopped after the 2011 economic crises.

\section{Shan State, Myanmar}

Shan State shows 59\% forest cover and rubber is the main tree crop (Table 1). Most rubber planting occurred after 2006 on forest lands (88\%); only 5\% of the deforestation in the region caused by rubber was in Shan State (Table 2); Figure 3 shows conversion of forests to large scale plantations. As in Laos, China established the Opium Replacement Program in 2004 to curb opium production and provided Chinese companies finical and bureaucratic support for investing in large-scale commercial agriculture in Myanmar ( $\mathrm{Lu}, 2017)$. Rubber was the main crop established through ORP support. In 2012 Myanmar passed the Farmland Law, the Vacant, Fallow, and Virgin lands Management Law, and the Forest Investment Law. These laws have enabled the granting of large scale concessions for tree crops. To date, most land concessions are being granted in upland areas particularly along the Thai and Chinese borders. This is partially 
because tenure in the uplands has historically been regulated by customary land, yet customary land-use rights are not formally recognized by the government (Scurrah, Hirsch, \& Woods, 2015). Figure 6 shows the area of rubber expansion in Shan State, Myanmar, Figure 5 the changes in rubber prices. As in Xishuangbanna, and to a lesser extent Laos, rubber planting basically stopped after the 2008 economic crises. There was a slight uptick in rubber planting after 2012 .

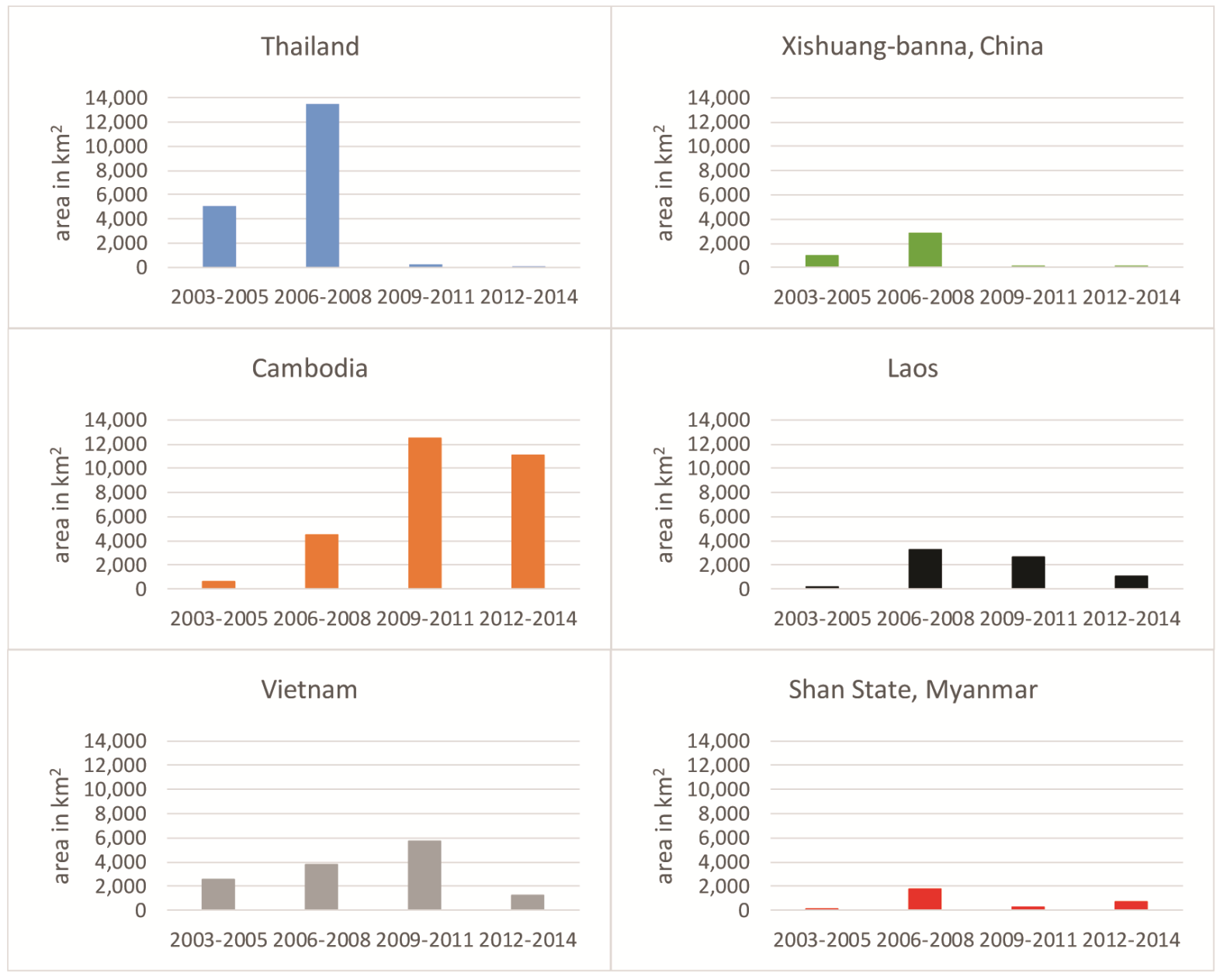

Figure 6: Error adjusted area of rubber expansion in Thailand, Cambodia, Vietnam, Laos, Shan State (Myanmar), and Xishuangbanna (China) as derived from land-cover change classification. 


\section{Discussion}

We performed a supervised change detection in an upscaling approach to classify land-cover dynamics with a focus on boom crops in MSEA using 16-day image composites of MODIS EVI and SWIR data from 2001-2014. In comparison with other mapping activities that focused on the MSEA region (e.g. Z. Li \& Fox, 2012; Miettinen, Shi, \& Liew, 2016; Stibig, Achard, Carboni, Raši, \& Miettinen, 2014) we obtained similar accuracies, but our map provides more detail on boom crop change and smallholder land-use practices (e.g. rotational agriculture). The map of Stibig et al. (2014) identified multiple forest types, plantations, and their change, but the analysis is based on a systematic sampling across MSEA, which can provide valuable information on e.g. forest loss in the region, but spatially explicit information on changes cannot be provided. The wall-to-wall map of Miettinen et al. (2016) also provides more detail on forest types in MSEA, but their map includes Insular Southeast Asia and they focused on large scale oil palm plantations while other dynamics related to tree plantations were grouped with the class 'regrowth'. Considering that land-use practices with crop-fallow rotation are widely practiced in MSEA, boom crops need to be mapped as a separate class to quantify land-use and land-cover changes. Li and Fox (2012) did this by focusing on rubber only. Their map provides valuable information on the distribution of young ( $<4$ years old) and old rubber in MSEA for 2010, but without information on change. Our map provides such detail, with information on plantation extents in 2014 (i.e. pulp trees, cashews, coffee, pineapple, fruit trees) and detailed information on conversions related to rubber and sugarcane. Dynamics can thus be analyzed for different periods and e.g. deforestation rates associated with the expansion of rubber quantified.

Our classification was performed in iterations and each iteration focused on improving classwise and overall accuracies by adjusting sample size of the classes through a random selection of 
points from a larger pool of samples and adapting the classification scheme. This allowed us to obtain an accurate classification of land-cover change with an overall accuracy for pure pixels of $82.2 \%$ and only four of the 24 classes show either UA or PA below $70 \%$. We found that classwise accuracies are affected by temporal heterogeneity of each class, area, and fragmentation; i.e. for small and fragmented classes (mostly the change classes) we usually obtained fewer points due to the MODIS pixel size. These change classes, however, would need more points to fully represent their temporal heterogeneity and obtain a reliable classification (Foody \& Arora, 1997; Hurni et al., 2017; Pal, 2005). During the iterations we focused on these issues (i.e. tradeoffs in accuracies in relation to class area, class heterogeneity, and sample sized) and by adjusting the number of sample points among classes we managed to obtain good accuracies for 20 classes and acceptable accuracies for the four remaining classes. We obtained our most accurate classifications when classes covered similar areas and represented similar dynamics (i.e. had similar spatio-temporal heterogeneity) and a similar number of sample points. Heydari and Mountrakis (2018) also demonstrated the importance of obtaining balanced numbers of sample points between classes when using machine learning classifiers; overall accuracies dropped significantly when using different size samples among the classes.

We evaluated the accuracy of the map using pure and mixed pixels and found that accuracies for mixed pixels were substantially lower, with an overall accuracy of $61.5 \%$ for pixels with a majority cover of $70-80 \%$ and of $43.4 \%$ for pixels with a majority cover of $50-60 \%$. For both, pure and mixed pixels, however, misclassification patterns are similar and the transformation classes (groups 2 and 3 ) show more errors. On the one hand the transformation classes mix with the corresponding 'from' class, e.g. 'rubber from evergreen forests' mixes with 'evergreen forests'. On the other hand the transformation classes mix with themselves, e.g. the type of 
change (from-to) is classified correctly, but the timing of the change is wrong or confusions with the class 'rotational agriculture' occur. The majority of the transformation classes (groups 2 and 3) show higher UA's than PA's and the difference between UA and PA usually increases with increasingly mixed pixels. We thus tend to underestimate the area covered by these classes and while we provide error adjusted area estimates based on the evaluation of pure pixels, we did not perform this for the mixed pixels. As a result our area estimates still show a certain bias and our calculations do not consider uncertainties related to mixed pixels. Due to the lower accuracy of mixed pixels, we can also expect that transformations that cover larger areas are classified more accurately compared to small scale dynamics.

Rubber caused deforestation in all countries in the region except Thailand, and even there it was planted on land deforested to plant annual crops. The expansion of rubber, however, has slowed as international prices have fallen (Figure 6). The Rubber Economist (2017) does not expect there to be another boom in rubber prices / demand in the short to medium term future, but they still forecast that the consumption of rubber (natural and synthetic) will increase from 27.52 million tons in 2016 to 29.41 million tons in 2017, i.e. an annual growth rate of $3.7 \%$. They predict that the growth pattern of the rubber industry for the next few years will remain slow but steady (The Rubber Economist, 2017). Already, we have seen a boom in bananas replacing rubber in northern Laos (Friis \& Nielsen, 2016), and frequent reports of cashews and black pepper being planted in northeast Cambodia as farmers diversify from planting more rubber (Thorng \& Chao, 2016).

While we may see a decrease in the expansion of rubber because of market prices, another problem may also soon affect rubber plantations — a shortage of labor. In precolonial Southeast Asia, land was more plentiful than labor. As Jim Scott writes (2009:24) 'Wars in precolonial 
Southeast Asia were less about territory than about the seizure of as many captives as possible who were then resettled at the core of the winner's territory.' Today, as industrial estates and plantations continue to develop, labor is again becoming a constraint on agriculture. This can be seen in the wages rubber plantations are paying to attract and maintain tappers despite low rubber prices on the global market. Fox et al. (under review) interviewed 69 tappers in Stung Treng, Cambodia; they reported an average wage of $\$ 157$ (640,000 Riel) per month; with a minimum of $\$ 20.00(80,000$ Riel) and a maximum of $\$ 270(1,100,000$ Riel). In addition to their wage, workers receive free housing, and a rice allowance per worker and per child. In comparison the Radio Free Asia (2017) reported that the minimum monthly wage for garment and footwear workers is $\$ 170$ a month. Clearly, in order to keep workers, plantation owners have to pay competitive wages.

Likewise in northern Laos, $\mathrm{Lu}$ (2017) reported that recruiting and training labor in Laos is proving far more difficult for companies than in China where rubber is much more established. One company manager noted that 'this year we're realizing there is a labor problem' (Luang Namtha, December 2012) while another stated, 'labor is the main bottleneck for rubber development here' (Luang Namtha, November 2012). Compared to China, Laos has an extremely limited labor supply.

Pholphirul (2013: 78) reports that in northern Thailand the option of hiring non-village labor applies not just to workers from other parts of Thailand, but also from neighboring countries. Increasingly, workers from Cambodia, Laos and Myanmar are working on Thai rice farms, fruit orchards and rubber estates. Rigg (2006) suggests the main cause of labor migration in Southeast Asia is the opportunity for higher income or higher wage rates and the ability to transfer money home. $\mathrm{Li}$ (2017) cautions that labor migration may not be a 'pathway out of poverty' but a 
temporary stop-gap for the extreme poor, who find themselves ejected when they become surplus to the requirements of their employers in the urban industrial sector (e.g., because of an economic downturn), without necessarily having the option simply to return home. Likewise, Barney (2012) in analyzing youth migration from central Laos to Thailand argues that decisions to migrate cannot be disconnected from broader issues of agrarian change. For example, the allocation of large areas of village land to powerful outsiders effectively coerces members of dispossessed households to migrate as a survival strategy.

Regardless of whether migration leads to higher incomes from non-farm employment (Manivong et al., 2014) or are a 'temporary stop-gap' on a downward spiral (T. M. Li, 2017), higher wages and the need for employers to compete for laborers in a tight labor market, will affect the profitability of rubber plantations. While the world will continue to consume natural rubber, the rate at which new rubber is planted may be slower for foreseeable future.

\section{Conclusions}

This project sought to map the extent of tree-based crops in the study region in 2014; and the expansion of rubber and sugarcane between 2003 and 2014. The map provides information on the extent of boom crops (e.g. cashews, pulp trees, coffee, and fruit trees) and detailed information on the expansion of sugarcane and rubber plantations for the MSEA region, allowing for a comparison between countries and sub-national regions. To our knowledge such detailed information has not so far been available at regional level and given the ecological and socioeconomic implications of boom crop expansion it can provide valuable insights on how dynamics vary across the region, e.g. the deforestation rates in different countries or administrative units associated with the expansion of rubber. We performed a supervised multi- 
date composite change detection technique using the random forest classifier in an upscaling approach. Previous research stressed the importance of obtaining sufficient sample points to represent the spatio-temporal heterogeneity of each class while balancing the number of points among classes to obtain good classification accuracies (Foody \& Arora, 1997; Heydari \& Mountrakis, 2018). We followed these suggestion and by iteratively adjusting class-wise sample size and the classification scheme, we managed to improve the accuracies of all classes and obtained high accuracies for most classes. It is important to note that we performed the selection of samples randomly by drawing from a larger pool of sample points. This guaranteed that accuracies, and thus the following classification iterations, were not biased by a targeted addition of sample points. Given the large number of sample points required by such a classification approach, future studies may assess how class-wise accuracies are affected by a reduction of the featurespace (i.e. using only a selection of MODIS bands that are most relevant for a specific classification problem). Grogan et al. (2016) showed that such a reduction of the featurespace affects classification accuracies only marginally but improves computational time, while other researchers obtained similar accuracies even by reducing the number of sample points (Pal, 2006).

We performed the accuracy assessment for pure pixels and for mixed pixels with a majority cover of $70-80 \%$ and for mixed pixels with a majority cover of $50-60 \%$. Similar to previous research working at MODIS resolution we found that sub-pixel changes occur and that such mixed pixels tend to show more misclassifications (Lunetta et al., 2006; Setiawan \& Yoshino, 2014). With increasingly mixed pixels classification accuracies decline and differences between UA and PA increase, which has implications for the calculation of error adjusted area estimates (Olofsson et al. 2014). In this study we based the error adjusted area estimates on the accuracy 
assessment of pure pixels. We, however, showed that with increasingly mixed pixels, accuracies also decline. Future research should address how to best include variations in mixed-pixel accuracies in error adjusted area estimates.

We found that in 2014, $25 \%$ of the landscape was covered by evergreen forest, $14 \%$ by deciduous forest, $13 \%$ by rotational agriculture, and $24 \%$ by low vegetation (mainly cereal crops but also scrub and bushes). In 2014 eight percent of the landscape was classified as rubber $\left(94,282 \mathrm{~km}^{2}\right)$; while cashews covered $1 \%$ of the landscape, coffee and fruit trees each covered $2 \%$, and pulp trees covered $4 \%$. Tree crops accounted for $18 \%$ of the landscape. Approximately $74,960 \mathrm{~km}^{2}$ of land were converted to rubber between 2003 and 2014; 70\% percent of the expansion of rubber plantations caused deforestation; while $30 \%$ occurred on areas previously covered by low vegetation (mainly crops). Our results nullified our hypothesis that boom crops were marked by intensification of previously used agricultural land and were not necessarily accompanied by deforestation. The expansion of rubber between 2003 and 2014 caused deforestation primarily in Cambodia and Laos, but also in Vietnam, Xishaungbanna, and Shan State.

We began this paper with the distinction between booms that have taken place under 'secure' conditions and those that have not (Hall et al. 2011). The maps we produced showing large scale land concessions for rubber in southern Laos and northeast Cambodia represent the 'insecure' booms' Hall argues that take place in areas imagined as 'frontiers' (Hall et al. 2011: 839). In northeast Thailand, northern Laos, Xishuangbanna, and Vietnam for the most part we find smallholder rubber plantations or what Hall et al. (2011:83) describe as 'secure' booms because 'the basic tenure relations that existed before the boom survive it.' The Rubber Economist (2017) estimates that most major rubber producing countries have a relatively high percentage share of 
smallholdings and the world share of natural rubber smallholding is around $73 \%$ of the total rubber area. As Hall et al. (2011:842) suggest various boom crops have been grown under many organizational frameworks, and while smallholders have successfully grown all of them, there is a fairly clear distinction between crops dominated by relatively independent smallholders (cocoa and coffee) and those where larger-scale production has been the rule (fast-growing trees and oil palm), with shrimp and rubber as intermediate cases. Clearly rubber can be grown as a successful smallholder crop.

As Fox and Castella (2013) suggest, in order to promote the establishment of a vibrant smallholder rubber sector the state needs to establish and effectively implement national policies and institutional structures to support smallholder rubber cultivators. National legislation needs to be developed that recognizes customary claims to land and grants farmers and farming communities legal access to the land they have traditionally used through either secure tenure on long-term use rights. In addition to access rights, national agencies need to support smallholders through integrate efforts to provide extension, credit, transport and marketing facilities such as that provided by the Offices of Rubber Replanting Aid Fund (ORRAF) in Thailand. It may also be useful to establish a governing and coordinating body to work closely with all sectors related to the rubber industry. At the local level, smallholder farmer groups need to be organized and/or supported in order to strengthen rubber cultivation, tapping, processing and marketing. These institutional arrangements need to be considered by policymakers as an imperative to support the sustainability and economic viability of smallholders' rubber production. Rubber smallholders may also benefit from advice on how to diversify their crop selection 


\section{References}

Akram-Lodhi, A. H. (2010). Review Essay: Land, Labour and Agrarian Transition in Vietnam. Journal of Agrarian Change, 10(4), 564-580. https://doi.org/10.1111/j.14710366.2010.00286.x

Baird, I. G. (2010). Land, rubber and people: Rapid agrarian change and responses in southern Laos. Journal of Lao Studies, 1(1), 47.

Baird, I. G. (2011). Turning Land into Capital, Turning People into Labor: Primitive Accumulation and the Arrival of Large-Scale Economic Land Concessions in the Lao People's Democratic Republic. New Proposals: Journal of Marxism and Interdisciplinary Inquiry, 5(1), 10-26.

Barney, K. (2008). China and the Production of Forestlands in Lao PDR: A Political Ecology of Transnational Enclosure. In J. Nevins \& N. L. Peluso, Taking Southeast Asia to Market: Commodities, Nature, and People in the Neoliberal Age (pp. 91-107). Cornell University Press.

Barney, K. (2012). Land, Livelihoods, and Remittances. Critical Asian Studies, 44(1), 57-83. https://doi.org/10.1080/14672715.2012.644887

Beck, P. S. A., Atzberger, C., Høgda, K. A., Johansen, B., \& Skidmore, A. K. (2006). Improved monitoring of vegetation dynamics at very high latitudes: A new method using MODIS NDVI. Remote Sens. Environ., 100(3), 321-334. https://doi.org/10.1016/j.rse.2005.10.021

Breiman, L. (2001). Random Forests. Machine Learning, 45(1), 5-32. https://doi.org/10.1023/A:1010933404324

Chen, B., Cao, J., Wang, J., Wu, Z., Tao, Z., Chen, J., Xie, G. (2012). Estimation of rubber stand age in typhoon and chilling injury afflicted area with Landsat TM data: A case study in Hainan Island, China. For. Ecol. Manage., 274, 222-230. https://doi.org/10.1016/j.foreco.2012.01.033

Clark, M. L., Aide, T. M., Grau, H. R., \& Riner, G. (2010). A scalable approach to mapping annual land cover at $250 \mathrm{~m}$ using MODIS time series data: A case study in the Dry Chaco ecoregion of South America. Remote Sens. Environ., 114(11), 2816-2832. https://doi.org/10.1016/j.rse.2010.07.001 
Cutler, D. R., Edwards, T. C., Beard, K. H., Cutler, A., Hess, K. T., Gibson, J., \& Lawler, J. J. (2007). Random Forests for Classification in Ecology. Ecology, 88(11), 2783-2792. https://doi.org/10.1890/07-0539.1

De Koninck, R. (2006). On the Geopolitics of Land Colonization: Order and Disorder on the Frontiers of Vietnam and Indonesia. Moussons. Recherche En Sciences Humaines Sur l'Asie Du Sud-Est, (9-10), 33-59. https://doi.org/10.4000/moussons.1977

De Koninck, R., Bernard, S., \& Bissonnette, J.-F. (2011). Borneo Transformed: Agricultural Expansion on the Southeast Asian Frontier. NUS Press.

DeFries, R. S., Townshend, J. R. G., \& Hansen, M. C. (1999). Continuous fields of vegetation characteristics at the global scale at 1-km resolution. J. Geophys. Res., 104(D14), 16,91116,923. https://doi.org/10.1029/1999jd900057

Eklundh, L., \& Jönsson, P. (2010). TIMESAT 3.0 - Software Manual (p. 74). Lund, Sweden: Lund University.

FAO. (2011). Southeast Asian Forests and Forestry to 2020: Subregional Report of the Second Asia-Pacific Forestry Sector Outlook Study (p. 78). Bangkok: Food and Agriculture Organization of the United Nations.

Foody, G. M., \& Arora, M. K. (1997). An evaluation of some factors affecting the accuracy of classification by an artificial neural network. International Journal of Remote Sensing, 18(4), 799-810. https://doi.org/10.1080/014311697218764

Fox, J., \& Castella, J.-C. (2013). Expansion of rubber (Hevea brasiliensis) in Mainland Southeast Asia: what are the prospects for smallholders? J. Peasant Stud., 40(1), 155-170. https://doi.org/10.1080/03066150.2012.750605

Fox, J., T. Nghiem, H. Kimkong, K. Hurni, and I. Baird. Under Review. Large-scale land concessions, migration, and land use: Industrial estates in the Red River Delta, and rubber plantations in Northeastern Cambodia.

Fox, J., \& Vogler, J. B. (2005). Land-use and Land-cover Change in Montane Mainland Southeast Asia. Environ. Manage., 36(3), 394-403. https://doi.org/10.1007/s00267-0030288-7

Friis, C., \& Nielsen, J. Ø. (2016). Small-scale land acquisitions, large-scale implications: Exploring the case of Chinese banana investments in Northern Laos. Land Use Policy, 57, 117-129. https://doi.org/10.1016/j.landusepol.2016.05.028 
Gérard, F., \& Ruf, F. (2001). Agriculture in Crisis: People, Commodities and Natural Resources in Indonesia, 1996-2000. Cirad.

Grogan, K., Pflugmacher, D., Hostert, P., Verbesselt, J., \& Fensholt, R. (2016). Mapping Clearances in Tropical Dry Forests Using Breakpoints, Trend, and Seasonal Components from MODIS Time Series: Does Forest Type Matter? Remote Sensing, 8(8), 657. https://doi.org/10.3390/rs8080657

Hall, D. (2003). The International Political Ecology of Industrial Shrimp Aquaculture and Industrial Plantation Forestry in Southeast Asia. Jnl. of SE Asian Studs., 34(02), 251-264. https://doi.org/10.1017/S0022463403000249

Hall, D., Hirsch, P., \& Li, T. (2011). Powers of Exclusion: Land Dilemmas in Southeast Asia. Honolulu: University of Hawai'i Press. Retrieved from https://market.android.com/details?id=book-A1puuQAACAAJ

Heydari, S. S., \& Mountrakis, G. (2018). Effect of classifier selection, reference sample size, reference class distribution and scene heterogeneity in per-pixel classification accuracy using 26 Landsat sites. Remote Sensing of Environment, 204, 648-658. https://doi.org/10.1016/j.rse.2017.09.035

Hird, J. N., \& McDermid, G. J. (2009). Noise reduction of NDVI time series: An empirical comparison of selected techniques. Remote Sens. Environ., 113(1), 248-258. https://doi.org/10.1016/j.rse.2008.09.003

Hurni, K., Hett, C., Heinimann, A., Messerli, P., \& Wiesmann, U. (2013). Dynamics of Shifting Cultivation Landscapes in Northern Lao PDR Between 2000 and 2009 Based on an Analysis of MODIS Time Series and Landsat Images. Hum. Ecol., 41(1), 21-36. https://doi.org/10.1007/s10745-012-9551-y

Hurni, K., Schneider, A., Heinimann, A., Nong, D., \& Fox, J. (2017). Mapping the Expansion of Boom Crops in Mainland Southeast Asia Using Dense Time Stacks of Landsat Data. Remote Sensing, 9(4), 320. https://doi.org/10.3390/rs9040320

IndexMundi. (2017). Retrieved October 5, 2017, from https://www.indexmundi.com/commodities/ 
Jakimow, B., Oldenburg, C., Rabe, A., Waske, B., van der Linden, S., \& Hostert, P. (2015). imageRF: Manual for application: imageRF (1.1) (p. 20). Berlin: Humboldt-Universitaet zu Berlin.

Jönsson, P., \& Eklundh, L. (2004). TIMESAT — a program for analyzing time-series of satellite sensor data. Comput. Geosci., 30(8), 833-845. https://doi.org/10.1016/j.cageo.2004.05.006

Kohavi, R. (1995). A Study of Cross-validation and Bootstrap for Accuracy Estimation and Model Selection. In IJCAI'95 (pp. 1137-1143). San Francisco, CA, USA: Morgan Kaufmann Publishers Inc. Retrieved from http://dl.acm.org/citation.cfm?id=1643031.1643047

Leblond, J. C. (2008). The retreat of agricultural lands in Thailand (ChATSEA Working Paper). University of Montreal.

Lestrelin, G., Castella, J.-C., \& Fox, J. (2013). Forest transitions in Southeast Asia : synergies and shortcomings in land-change science and political ecology. In C. Braanstrom \& J. Vadjunec (Eds.), Land change science, political ecology, and sustainability: synergies and divergences (pp. 48-65). Oxon: Routledge. Retrieved from http://www.documentation.ird.fr/hor/fdi:010060140

Li, T. M. (2017). Intergenerational displacement in Indonesia's oil palm plantation zone. The Journal of Peasant Studies, 44(6), 1158-1176. https://doi.org/10.1080/03066150.2017.1308353

Li, Z., \& Fox, J. M. (2011). Integrating Mahalanobis typicalities with a neural network for rubber distribution mapping. Remote Sens. Lett., 2(2), 157-166. https://doi.org/10.1080/01431161.2010.505589

Li, Z., \& Fox, J. M. (2012). Mapping rubber tree growth in mainland Southeast Asia using timeseries MODIS $250 \mathrm{~m}$ NDVI and statistical data. Appl. Geogr., 32(2), 420-432. https://doi.org/10.1016/j.apgeog.2011.06.018

Lu, J. N. (2017). Tapping into rubber: China's opium replacement program and rubber production in Laos. The Journal of Peasant Studies, 44(4), 726-747. https://doi.org/10.1080/03066150.2017.1314268 
Lunetta, R. S., Knight, J. F., Ediriwickrema, J., Lyon, J. G., \& Worthy, L. D. (2006). Land-cover change detection using multi-temporal MODIS NDVI data. Remote Sens. Environ., 105(2), 142-154. https://doi.org/10.1016/j.rse.2006.06.018

Manivong, V., Cramb, R., \& Newby, J. (2014). Rice and Remittances: Crop Intensification Versus Labour Migration in Southern Laos. Human Ecology, 42(3), 367-379. https://doi.org/10.1007/s10745-014-9656-6

Meyfroidt, P., \& Lambin, E. F. (2009). Forest transition in Vietnam and displacement of deforestation abroad. Proc. Natl. Acad. Sci. U. S. A., 106(38), 16139-16144. https://doi.org/10.1073/pnas.0904942106

Miettinen, J., Shi, C., \& Liew, S. C. (2016). 2015 Land cover map of Southeast Asia at $250 \mathrm{~m}$ spatial resolution. Remote Sens. Lett., 7(7), 701-710. https://doi.org/10.1080/2150704X.2016.1182659

Olofsson, P., Foody, G. M., Herold, M., Stehman, S. V., Woodcock, C. E., \& Wulder, M. A. (2014). Good practices for estimating area and assessing accuracy of land change. Remote Sens. Environ., 148, 42-57. https://doi.org/10.1016/j.rse.2014.02.015

Open Development Cambodia (ODC). (2017). Retrieved October 15, 2017, from https://opendevelopmentcambodia.net/

Pal, M. (2005). Random forest classifier for remote sensing classification. Int. J. Remote Sens., 26(1), 217-222. https://doi.org/10.1080/01431160412331269698

Pal, M. (2006). Support vector machine-based feature selection for land cover classification: a case study with DAIS hyperspectral data. Int. J. Remote Sens., 27(14), 2877-2894. https://doi.org/10.1080/01431160500242515

Pholphirul, P. (2013). Labour Migration and the Economic Sustainability in Thailand. Journal of Current Southeast Asian Affairs, 31(3), 59-83.

Radio Free Asia. (2017). Cambodian Garment and Footwear Workers to Get Minimum Wage Hike by 2018. Retrieved October 11, 2017, from https://www.rfa.org/english/news/cambodia/textile-wages-10052017171647.html

Rigg, J. D. (2006). Forests, marketization, livelihoods and the poor in the Lao PDR. Land Degrad. Dev., 17(2), 123-133. https://doi.org/10.1002/ldr.719 
Rodriguez-Galiano, V. F., \& Chica-Rivas, M. (2014). Evaluation of different machine learning methods for land cover mapping of a Mediterranean area using multi-seasonal Landsat images and Digital Terrain Models. International Journal of Digital Earth, 7(6), 492509. https://doi.org/10.1080/17538947.2012.748848

Schmidt-Vogt, D., Leisz, S. J., Mertz, O., Heinimann, A., Thiha, T., Messerli, P., Dao, T. M. (2009). An Assessment of Trends in the Extent of Swidden in Southeast Asia. Hum. Ecol., 37(3), 269. https://doi.org/10.1007/s10745-009-9239-0

Schneider, A. (2012). Monitoring land cover change in urban and peri-urban areas using dense time stacks of Landsat satellite data and a data mining approach. Remote Sens. Environ., 124, 689-704. https://doi.org/10.1016/j.rse.2012.06.006

Scott, J. C. (2009). The Art of Not Being Governed: An Anarchist History of Upland Southeast Asia. Yale University Press.

Scurrah, N., \& Hirsch, P. (2015). The Political Economy of Land Governance in Cambodia (p. 32). Vientiane, Lao PDR: Mekong Region Land Governance (MRLG). Retrieved from http://mrlg.org/wpcontent/uploads/2015/12/Political_Economy_of_Land_Governance_in_Cambodia.pdf

Scurrah, N., Hirsch, P., \& Woods, K. (2015). The Political Economy of Land Governance in Myanmar (p. 33). Vientiane, Lao PDR: Mekong Region Land Governance (MRLG). Retrieved from http://mrlg.org/wpcontent/uploads/2015/12/Political_Economy_of_Land_Governance_in_Myanmar_FA_2. pdf

Setiawan, Y., \& Yoshino, K. (2014). Detecting land-use change from seasonal vegetation dynamics on regional scale with MODIS EVI 250-m time-series imagery. J. Land Use Sci., 9(3), 304-330. https://doi.org/10.1080/1747423X.2013.786151

Stibig, H.-J., Achard, F., Carboni, S., Raši, R., \& Miettinen, J. (2014). Change in tropical forest cover of Southeast Asia from 1990 to 2010. Biogeosciences, 11(2), 247-258. https://doi.org/10.5194/bg-11-247-2014

Suepa, T., Qi, J., Lawawirojwong, S., \& Messina, J. P. (2016). Understanding spatio-temporal variation of vegetation phenology and rainfall seasonality in the monsoon Southeast Asia. Environ. Res., 147, 621-629. https://doi.org/10.1016/j.envres.2016.02.005 
The Rubber Economist. (2017). The Rubber Economist Quarterly Report: Third Quarter 2017. Bangkok and London: The Rubber Economist Ltd. Retrieved from http://therubbereconomist.com/Home.html

Thorng, R., \& Chao, S. (2016). Contract Farming Arrangements In Cambodia: The Case Of Kampot Pepper (Piper Nigrum). Journal of Mekong Societies, 12(2), 45-69. https://doi.org/10.14456/jms.2016.14

Tottrup, C., Rasmussen, M. S., Eklundh, L., \& Jönsson, P. (2007). Mapping fractional forest cover across the highlands of mainland Southeast Asia using MODIS data and regression tree modelling. Int. J. Remote Sens., 28(1), 23-46. https://doi.org/10.1080/01431160600784218

USGS. (2017). Land Processes Distributed Active Archive Center (LP DAAC). Retrieved November 10, 2017, from https://lpdaac.usgs.gov/dataset_discovery/modis/modis_products_table/mod13q1 van der Linden, S., Rabe, A., Held, M., Jakimow, B., Leitão, P., Okujeni, A., Hostert, P. (2015). The EnMAP-Box-A Toolbox and Application Programming Interface for EnMAP Data Processing. Remote Sensing, 7(9), 11249-11266. https://doi.org/10.3390/rs70911249

Vityakon, P., Subhadhira, S., Limpinuntana, V., Srila, S., Trelo-Ges, V., \& Sriboonlue, V. (2004). From Forest to Farmfields. Japanese Journal of Southeast Asian Studies, 41(4), 444-472.

Ziegler, A. D., Fox, J. M., \& Xu, J. (2009). Agriculture. The rubber juggernaut. Science, 324(5930), 1024-1025. https://doi.org/10.1126/science.1173833 


\section{Supplementary Material}
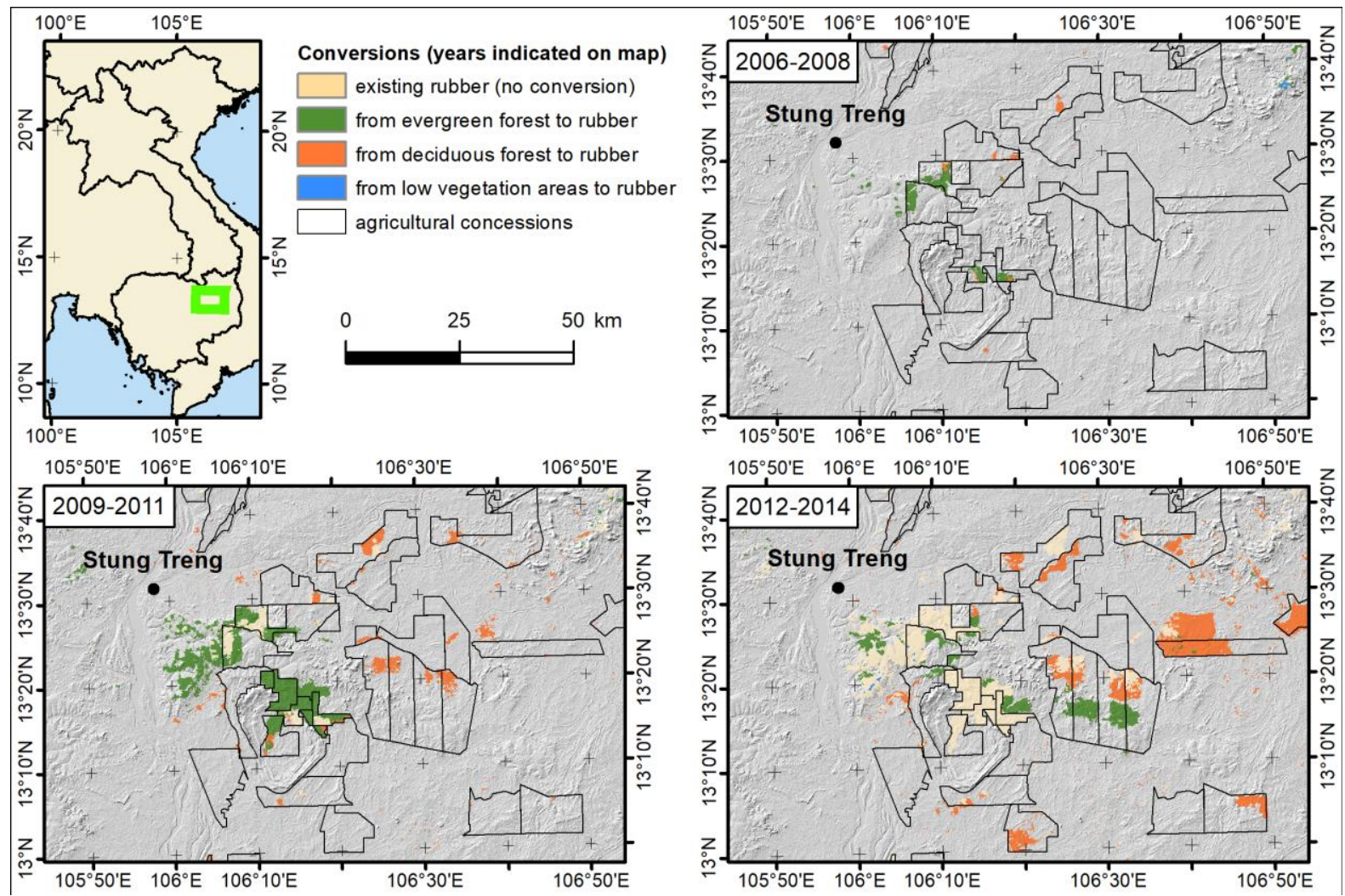

Figure A: Conversions to rubber by year and conversion type around Stung Treng, Cambodia. Black outlined areas represent economic land concessions granted by the government of Cambodia for plantation crops. 
Table A: Accuracy assessment of the classification for pure pixels and mixed pixels. For the evaluation of the mixed pixels, we selected areas where the main land-cover (change) class covers $70-80 \%$ and 50 $60 \%$ of the MODIS pixel. Overall accuracies range from $82.2 \%$ (pure pixels) to $61.5 \%$ (70-80\% pure pixels) and 43.4\% (50-60\% pure pixels).

\begin{tabular}{|c|c|c|c|c|c|c|c|c|c|}
\hline \multirow[b]{2}{*}{ Land-cover (change) class } & \multicolumn{3}{|c|}{ Pure pixels } & \multicolumn{3}{|c|}{$70-80 \%$ pure pixels } & \multicolumn{3}{|c|}{$50-60 \%$ pure pixels } \\
\hline & UA & PA & Samples & UA & PA & Samples & UA & PA & Samples \\
\hline Water & 96 & 95 & 300 & 95.8 & 46.0 & 300 & 84.1 & 24.7 & 300 \\
\hline Evergreen forests $(\mathrm{F})$ & 83 & 89.4 & 918 & 70.0 & 62.2 & 918 & 53.2 & 41.6 & 918 \\
\hline Deciduous forests (DF) & 82.2 & 87.5 & 569 & 54.2 & 72.6 & 569 & 31.8 & 52.0 & 569 \\
\hline Low vegetation areas (LVA) & 77.9 & 90.2 & 735 & 58.5 & 80.8 & 735 & 37.9 & 62.3 & 735 \\
\hline Rubber (before 2003) & 86.9 & 83.5 & 256 & 89.5 & 66.4 & 256 & 83.5 & 45.3 & 256 \\
\hline Pineapple & 97.9 & 93.9 & 100 & 95.0 & 76.0 & 100 & 94.3 & 33.0 & 100 \\
\hline Rubber, from F, 2003-2005 & 95.2 & 79 & 100 & 75.8 & 47.0 & 100 & 63.6 & 21.0 & 100 \\
\hline Rubber, from LVA, 2003-2005 & 79.2 & 77.6 & 100 & 52.3 & 69.0 & 100 & 36.3 & 53.0 & 100 \\
\hline Rubber, from F, 2006-2008 & 85.6 & 88.3 & 350 & 80.9 & 66.6 & 350 & 70.9 & 45.1 & 350 \\
\hline Rubber, from DF, 2006-2008 & 92.2 & 71 & 100 & 78.1 & 50.0 & 100 & 78.4 & 29.0 & 100 \\
\hline Rubber, from LVA, 2006-2008 & 85.1 & 65.5 & 150 & 60.2 & 53.3 & 150 & 44.3 & 38.7 & 150 \\
\hline Rubber, from F, 2009-2011 & 87.1 & 79.1 & 360 & 81.1 & 53.6 & 360 & 67.5 & 37.5 & 360 \\
\hline Rubber, from DF, 2009-2011 & 89.9 & 83.7 & 202 & 74.3 & 54.5 & 202 & 56.9 & 36.6 & 202 \\
\hline Rubber, from F, 2012-2014 & 89.2 & 71.8 & 150 & 78.0 & 56.7 & 150 & 65.9 & 36.0 & 150 \\
\hline Rubber, from DF, 2012-2014 & 81.8 & 81 & 100 & 53.3 & 49.0 & 100 & 44.2 & 34.0 & 100 \\
\hline Sugarcane, from F, 2006-2008 & 100 & 97.9 & 100 & 100.0 & 100.0 & 6 & 66.7 & 50.0 & 4 \\
\hline Sugarcane, from DF, 2009-2011 & 100 & 89.5 & 19 & 0.0 & 0.0 & 1 & 0.0 & 0.0 & 2 \\
\hline Rotational Agriculture & 62.5 & 70.4 & 706 & 37.0 & 61.8 & 706 & 25.5 & 49.2 & 706 \\
\hline $\begin{array}{l}\text { Expansion of LVA / } \\
\text { intensification }\end{array}$ & 80.7 & 67.2 & 356 & 74.7 & 59.8 & 356 & 55.8 & 42.1 & 356 \\
\hline New Water & 100 & 91.9 & 100 & 97.5 & 39.0 & 100 & 95.8 & 23.0 & 100 \\
\hline Pulp trees & 78.2 & 74.7 & 400 & 66.1 & 65.0 & 123 & 64.2 & 54.6 & 273 \\
\hline Cashews & 92.7 & 74.5 & 156 & 68.4 & 25.0 & 156 & 45.5 & 12.8 & 156 \\
\hline Fruit trees & 84.5 & 68 & 202 & 57.0 & 44.6 & 202 & 36.9 & 36.1 & 202 \\
\hline Coffee & 87.5 & 88.9 & 320 & 41.0 & 54.8 & 62 & 42.4 & 34.0 & 106 \\
\hline
\end{tabular}

